\title{
The Coordination Chemistry at Gold Nanoparticles
}

\author{
Henrique E. Toma,* Vitor M. Zamarion, Sergio H. Toma and Koiti Araki \\ Instituto de Química, Universidade de São Paulo, 05508-000 São Paulo-SP, Brazil
}

\begin{abstract}
Nas nanopartículas de ouro, as propriedades químicas e físicas são ditadas principalmente pelos átomos da superfície, os quais podem interagir com espécies doadoras-aceitadoras, ou ligantes, da mesma forma que os complexos metálicos correspondentes. Além disso, os elétrons podem entrar em ressonância com a luz incidente dando origem aos plasmons de superfície, que levam à intensificação do campo elétrico local e ao efeito SERS, proporcionando uma ampla variedade de aplicações na química, biologia e nanotecnologia. Ligantes de ponte, multifuncionais, podem ser usados para intermediar a ligação de íons metálicos aos átomos de ouro da superfície. Essa estratégia permite controlar a estabilização em solução através das cargas dos complexos metálicos, acrescentando, ao mesmo tempo, novas características químicas e maior funcionalidade às nanopartículas modificadas. Dessa forma, uma nova química de coordenação pode ser vislumbrada, combinando nanopartículas metálicas, como as de ouro, e complexos, à luz da química supramolecular e dos efeitos de ressonância plasmônica de superfície.
\end{abstract}

In gold nanoparticles the surface metal atoms play a major role, determining their chemical and physical properties by interacting with donor-acceptor species or ligands in a similar way as the related metal complexes. In addition, coherent oscillations of the metal electrons in resonance with the frequency of the exciting light give rise to localized surface plasmons responsible for an enhancement of the local electric field and SERS effect, allowing a wide range of applications in chemistry, biology and nanotechnology. Multifunctional bridging ligands can be employed for simultaneously binding metal ions and surface atoms. The attractive point of this approach is the possibility of exploiting the charge controlled stabilization by the metal complexes, while imparting new characteristics and properties to the modified nanoparticles. As a matter of fact, a new, exciting field of coordination chemistry can be envisaged, combining metal nanoparticles and metal complexes, in the light of supramolecular and surface plasmon resonance effects.

Keywords: gold nanoparticles, supramolecular chemistry, SPR, plasmon resonance, SERS

\section{Introduction}

Gold is considered a very special element for its historical and economical role, and for its beautiful shiny color, widely used for decorating precious paintings, ceramics and tapestries. Its chemistry has been extensively exploited in catalysis, medicine and in the generation of interesting cluster complexes. After the classical Faraday work $^{1}$ on the preparation of gold colloids, it became apparent that the bright red colors of ancient paints and stained glass windows were due to this element in a finely dispersed form. Now, it is known that Faraday's red colloidal solutions consist of gold nanoparticles, which have remained surprisingly stable along the last 150 years.

However, what makes gold really special are the remarkable surface properties of its nanoparticles. ${ }^{2}$ At the

*e-mail: henetoma@iq.usp.br nanoscale, a large fraction of atoms are concentrated at the nanoparticle surface, playing a major role in its chemical and physical properties. In fact, surface atoms seem to exhibit incomplete valence, in the sense that they are only bound to the internal atoms, thus keeping external sites available for interacting with donor-acceptor species, or ligands. For this reason, metal nanoparticles can show similar behavior as their related metal complexes, forming selective chemical bonds with appropriate ligands. However, up to the present time, in spite of the numerous review articles on metal surfaces and nanoparticles available in the literature, ${ }^{3-6}$ from the point of view of the coordination chemistry involved, most of the fundamental aspects have been dealt with only on an intuitive basis. Systematic studies exploring the chemical analogies between metal nanoparticles and metal complexes remain rather scarce. ${ }^{7,8}$

In the case of gold nanoparticles, additional interest is brought about by the existence of the so called surface 
plasmons. ${ }^{9}$ Under the influence of electromagnetic radiation, the electrons of the surface atoms can easily move through the vacant orbitals. The coherent oscillations of those electrons in resonance with the frequency of the light give rise to localized surface plasmons, which can be explored in a wide range of applications in chemistry, biology and nanotechnology. ${ }^{4,6}$ Most applications require the stabilization of the nanoparticles as colloidal dispersions by means of surface modification with suitable coordinating species, such as citrate ions, thiols or surfactants. The stabilization of gold nanoparticles can also be conveniently performed by means of multifunctional bridging ligands, capable of simultaneously binding transition metal ion complexes and the gold atoms at the surface. The attractive point of this approach is the possibility of controlling the stability of the dispersions by exploiting the charge and steric properties of the metal complexes, while imparting their characteristics and properties to the modified nanoparticles.

This review article is focused on the coordination chemistry at the gold nanoparticles (AuNPs) surface, including fundamental aspects such as the preparation and stabilization of the nanoparticles, and the discussion of the extinction spectra and surface plasmon resonance effects. The exciting perspectives of the surface enhanced Raman spectroscopy (SERS) ${ }^{10,11}$ have also been explored in great detail.

\section{Preparation of Gold Nanoparticles}

Spherical gold nanoparticles can be generated in aqueous solution by the citrate reduction method reported by Turkevitch et al..$^{12}$ in 1951, and improved by Frens ${ }^{13}$ in 1973. Essentially, the reaction takes place when an aqueous reaction mixture of gold chloride (or tetrachloric acid, $\mathrm{HAuCl}_{4}$ ) and sodium citrate is heated under stirring. The temperature, the stirring rate, the ratio of gold to citrate and the order of addition of the reagents influence the size distribution of the nanoparticles.

Large spherical and nonspherical nanoparticles can be generated using the seeding technique. ${ }^{5}$ In this case, small, spherical nanoparticles are first generated in the presence of a strong reducing agent such as sodium borohydride, and are then added to a growth solution containing more of the metal ions that will be deposited onto the seeds. A weaker reducing agent, such as ascorbic acid, is usually employed in the growth solution. The growth process is believed to be kinetically controlled, in such a way that the metal salt is first reduced to an intermediate state so that only the catalyzed reduction on the nanoparticle surface is allowed. Surfactants can be added to induce anisotropic growth. For example, the seed, salt and stabilizer concentrations and other parameters can be adjusted to generate nanorods.

Very small nanoparticles with narrow size dispersion can be prepared using a two-phase process in the presence of organic thiols. In the method proposed by Brust et al. ${ }^{14}$ the gold salt is dissolved in water and first transferred to the organic phase using a suitable phase-transfer agent, such as tetraoctylammonium bromide. Then, an aqueous sodium borohydride solution is added to the stirred biphasic system, leading to the formation of gold nanoparticles, changing the organic phase color from the characteristic orange to red or brown, depending on the size. The ratio of gold to the organothiol and the reaction temperature control the particle size. The nanoparticles, protected by a compact shell of organothiols, are stable for long periods of time, either in solution or as solids that can be readily redispersed in organic solvents. Many variations of this method are possible, including the modification proposed by Araki et al. ${ }^{15}$ that allows the preparation of reactive gold nanoparticles protected by a shell of tert-dodecanethiol. This was achieved by interrupting the conventional Brust reaction, separating the organic phase (toluene), concentrating and precipitating the AuNPs with methanol within about an hour, before a compact layer of tert-dodecanethiol is formed. In this way, nanoparticles are obtained which are stable enough but still exhibit a reactive surface. Such materials can be easily redispersed in toluene and employed for further functionalization with suitable species.

Other synthetic methods include electrochemical, sonochemical, thermal and photochemical reduction techniques. ${ }^{4,5,16,17}$ Ionic liquids can also be employed; however, the reduction of $\mathrm{Ag}^{+}$or $\mathrm{Au}^{3+}$ to the zero valent state is susceptible to thermodynamic and kinetic effects, yielding nanoparticles, nanowires and clusters. ${ }^{18}$ In the case of imidazolium ionic liquids, the stabilization of gold nanoparticles was found to be associated with the disclosure of the imidazolium cation. ${ }^{19}$ Inverse micelles have been used to generate nanoparticles exhibiting appreciable degree of size and shape control ${ }^{17,20}$ by providing effective nanoreactors with narrow size dispersion. On the other hand, these species can adsorb preferentially on some crystalline faces, promoting a faster growth of the less protected faces, leading to anisotropic particles such as nanorods. Accordingly, the nature and concentration of the surfactants and the ligands, the temperature, and the relative volumes of the aqueous and organic phases should be controlled, since they influence the micelle size. 


\section{Extinction Spectra of Gold Nanoparticles}

Atoms of noble metals such as $\mathrm{Au}$ and $\mathrm{Ag}$, as well as the related $\mathrm{Cu}$ element, exhibit completely filled $5 \mathrm{~d}$, $4 \mathrm{~d}$ or $3 \mathrm{~d}$ shells, respectively, but only one electron in the corresponding $6 \mathrm{~s}, 5 \mathrm{~s}$ or $4 \mathrm{~s}$ levels. Their atomic spectra are dominated by the electronic transitions involving the several quantum levels associated with the $(\mathrm{n}-1) \mathrm{d}$ and $\mathrm{n}(\mathrm{s}, \mathrm{p})$ shells. Bulk gold has a typical yellow color arising from the increasing reflectivity as the interband transition in the visible, involving the broad conduction band, is approached. This band is mainly derived from the $\mathrm{s}$ and $\mathrm{p}$ orbitals which are strongly influenced by the $\mathrm{d}^{10}$ core. According to Maxwell theory, the reflection of light at metallic surfaces is proportional to the imaginary part of the dielectric term associated with the absorption phenomenon. As a consequence, paradoxically, gold metal reflects more efficiently at wavelengths in which the radiation is most strongly absorbed. ${ }^{21}$

Gold nanoparticles exhibit characteristic colors and properties that are absent in the individual atoms, as well as in the bulk material. In the case of spherical nanoparticles much smaller than the wavelength of light, the average electric field induced by light $\left(\mathrm{E}_{\mathrm{o}}\right)$ can be considered constant, so that all nanoparticle electrons are submitted to the same electromagnetic field. In some cases, however, the electromagnetic field of frequency $v$ is capable of inducing a collective oscillation of the electrons at the conduction band of the metal, propagating like a plasmon wave. Considering that the atoms nuclei are still, the oscillation of the electrons leads to a periodic charge separation and generates oscillating dipoles whose magnitude reaches a maximum at the nanoparticles surface (Figure 1). The frequency of such oscillating dipoles depends upon the dielectric constant of the bulk and the surroundings, as well as on the electric field inside the particle, $\mathrm{E}_{\mathrm{i}}$. This is expressed by equation 1 ,

$E_{i}=E_{o}\left[\frac{3 \varepsilon_{m}}{\left(\varepsilon+2 \varepsilon_{m}\right)}\right]$

where $\varepsilon_{\mathrm{m}}$ is the dielectric constant of the surrounding medium and $\varepsilon$ is the dielectric constant of the metal particle.

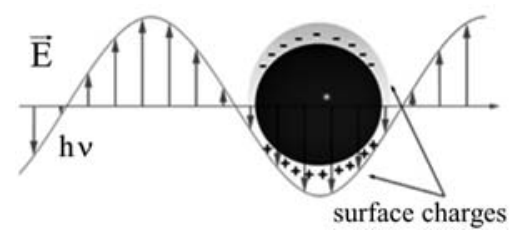

Figure 1. Oscillating dipoles induced by electromagnetic radiation at gold nanoparticles.
The induced dipole moment that results from the electronic polarization is given by equation 2

$p=\varepsilon_{m} \alpha E_{o}$

where

$\alpha=4 \pi \varepsilon_{o} R^{3} \frac{\left(\varepsilon-\varepsilon_{m}\right)}{\left(\varepsilon+2 \varepsilon_{m}\right)}$

and $\mathrm{R}$ is the radius of the particle. A modifying field factor, $g$, can be defined as

$g=\frac{\varepsilon-\varepsilon_{m}}{\varepsilon+2 \varepsilon_{m}}$

so that the polarizability term becomes

$\alpha=4 \pi \varepsilon_{o} g R^{3}$

On the other hand, the dielectric constant of the metal, $\varepsilon$, is frequency dependent, involving a real and an imaginary part, as expressed by equation 6 ,

$\varepsilon=\varepsilon_{1}(\omega)+i \varepsilon_{2}(\omega)=(\eta+i \kappa)^{2}$

where $\eta$ is the refractive index and $\kappa$ is the absorption coefficient. The wavelength dependence of the plasmon resonance is associated with the dielectric constants $\varepsilon_{1}(\omega)$ and $\varepsilon_{2}(\omega)$, where $\omega$ is the frequency of the exciting light. The decay from the excited plasmon states can occur radiatively or non-radiatively, giving rise to enhanced scattering and absorption at the frequency $\omega$. Such optical properties are actually embedded in the extinction spectra, and the measured absorbance (A) is given by

$A=\frac{N \sigma_{e x t} d}{2.303}$

where $\sigma_{\text {ext }}$ is the extinction cross-section, $d$ is the sample pathlength and $\mathrm{N}$ is the nanoparticle concentration.

By solving the Maxwell equations for the interaction of light with nanoparticles of radius much smaller than the electromagnetic wavelength, Mie, ${ }^{22}$ in 1908 , successfully derived the theoretical equation 8 for $\sigma_{\text {ext }}$

$\sigma_{\text {ext }}=9\left(\frac{\omega}{c}\right) \varepsilon_{m}^{3 / 2} V\left(\frac{\varepsilon_{2}(\omega)}{\left[\varepsilon_{1}(\omega)+2 \varepsilon_{m}\right]^{2}+\left[\varepsilon_{2}(\omega)\right]^{2}}\right)$

where $V=(4 \pi / 3) R^{3}$ is the volume of the spherical particle and $\mathrm{c}$ is the velocity of light. The plot of the $\sigma_{\text {ext }}$ values as a function of the excitation frequency gives the extinction 
spectra of the nanoparticles including the plasmon transitions. According to Mie's equation, if $\varepsilon_{2}$ is relatively small, a resonance condition is attained when $\varepsilon_{1}(\omega)=-2 \varepsilon_{\mathrm{m}}$, corresponding to the maximum absorption observed in the extinction spectrum (Figure 2). As a matter of fact, a reasonable spectral fitting is usually provided by Mie's theory in the case of spherical nanoparticles.

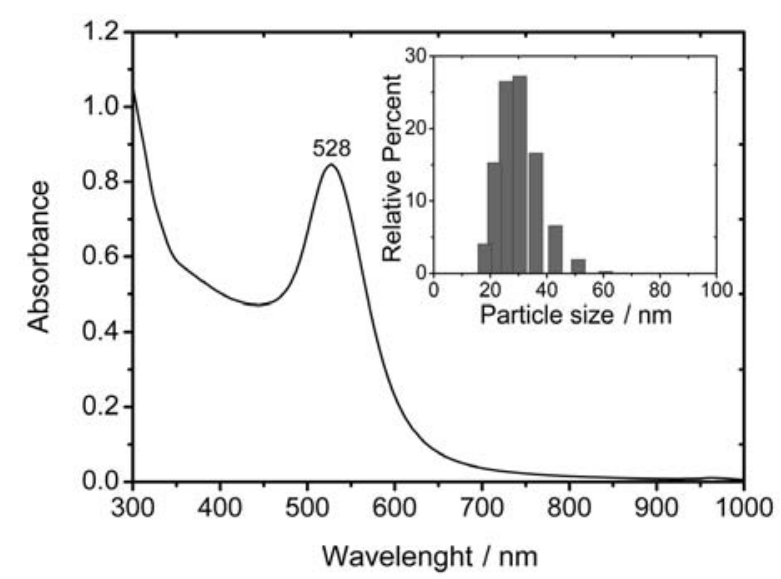

Figure 2. Typical extinction spectrum of spherical gold nanoparticles (inset $=$ the corresponding size distribution of the nanoparticles).

However, it should be noticed that the surface plasmon oscillations in metallic nanoparticles are dependent on the shape, showing remarkable changes when they are non-spherical. To deal with those cases, Mie's theory was modified in order to include the contributions of two distinct longitudinal and transverse dipole polarization modes. As a consequence, in contrast to a single plasmon band, two bands became apparent, associated with the transverse and longitudinal plasmon resonances (Figure 3). Typically, the transverse mode shows a resonance coinciding with the plasmon band of spherical particles, e.g. at $520 \mathrm{~nm}$, while the resonance of the longitudinal mode is red-shifted,

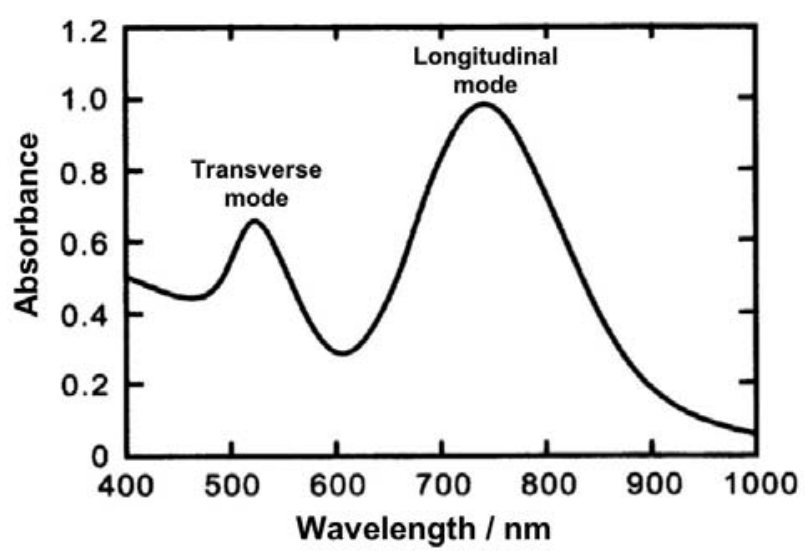

Figure 3. Typical extinction spectra of non-spherical nanoparticles, showing the bands assigned to the transverse and longitudinal plasmon resonance modes. usually appearing above $700 \mathrm{~nm}$. The resonance frequency is strongly dependent on the aspect ratio, which is defined as the ratio of length to width of non-spherical nanoparticles such as rods.

The surface plasmon oscillation is also drastically changed if the nanoparticles agglomerate at some extent, allowing the individual particles to electronically couple to each other. It has been shown that the electromagnetic coupling of nanoparticles becomes effective when the interparticle distances are smaller than 5 times their individual radius. ${ }^{11}$ Agglomeration can promote the coupling of the gold nanoparticles plasmon modes, generating a new band encompassing a red shift and broadening, associated with the longitudinal resonance in the optical spectrum. As a consequence, agglomeration usually changes the initial red color of the AuNPs dispersion into blue. The resulting spectra are composed by the intrinsic bands of the spherical nanoparticles and a new band, arising from interparticle plasmon coupling.

As shown by Mirkin et al. ${ }^{23}$ biomolecular recognition can trigger the assembly of nanoparticles, such that the spectral changes can be utilized to detect DNA and protein biomarkers for cancer and other diseases. Applications of gold nanoparticles are now widespread in medicine. ${ }^{24}$

Since the interparticle coupling is stronger than the interaction with the surroundings, Mie's theory, originally developed for isolated particles, fails to describe the optical absorption spectra of aggregated nanoparticles. In this case, an alternative theory employing the effective medium approach has been proposed by Maxwell and Garnett in $1904,{ }^{25}$ to account for the optical behavior of metal nanoparticles in a closely packed assembly. According to this theory, the optical properties of nanoparticles are mainly determined by their isolated individual behavior and the collective properties of the whole ensemble. In order to model the influence of interparticle coupling, an explicit knowledge of the statistical variation of the position and pairwise distances of all particles is necessary. This is a rather complicated task, but a great simplification has been obtained using the discrete dipole approximation proposed by Purcell and Pennypacker in $1973 .{ }^{26}$ In this treatment, the nanoparticles in the aggregate are considered as polarizable elements that are coupled together in order to determine the overall polarization response.

\section{Plasmon Resonance and SERS}

In metal nanoparticles, the coherent oscillations of the electrons in resonance with the electromagnetic radiation of frequency $\omega_{\mathrm{o}}$ are also referred as localized surface plasmon resonance (LSPR), corresponding to an oscillating induced 
dipole, $\mathrm{p}_{\mathrm{o}}$, and its corresponding $\mathrm{g}_{\mathrm{o}}$ term (equations 2 and 4 ). LSPR generates a strongly enhanced electric near-field $\left(\mathrm{E}_{\mathrm{s}}\right)$ at the nanoparticle surface, which forms the basis of the electromagnetic surface-enhanced Raman spectroscopy. An adsorbed molecule with polarizability $\alpha_{M}$ will be affected by the near-field $E_{s}$, behaving as an oscillating dipole, $p_{1}=\alpha_{M} E_{s}$. This dipole will also induce a secondary component $\left(\mathrm{p}_{2}\right)$ in the far field, also referred as scattered field.

In the far field, or radiation zone, the detected Raman field for the nanoparticle-molecule will have the contributions of the two induced dipoles, $\mathrm{p}_{1}$ and $\mathrm{p}_{2}$, oscillating with a shifted frequency $(\omega)$, corresponding to the inelastically scattered or Raman frequency. The total radiated power is proportional to $\left[p_{1}+p_{2}\right]^{2}$. It should be compared with the power radiated by the molecules in the absence of the nanoparticles, i.e., $\mathrm{p}_{\mathrm{M}}{ }^{2}$, in order to evaluate the enhancement factor, EF.

Kerker at al. ${ }^{27}$ derived a very useful expression for EF (equation 9):

$E F=\frac{\left[p_{1}+p_{2}\right]^{2}}{p_{M}{ }^{2}}=5\left[1+2 g_{o}+2 g+4 g g_{o}\right]^{2}$

in which the dominant term at the resonance frequency is $4 \mathrm{gg}_{0}$. Accordingly, the resonance condition embedded in the $\mathrm{g}$ fator, i.e., $\varepsilon_{1}(\omega)=-2 \varepsilon_{\mathrm{m}}$ in equation 4 , shows that the SERS enhancement will be operative only for materials which can be optically tuned in the spectral region of excitation $\left(\omega_{0}\right)$.

In practice, as Aroca has pointed out, ${ }^{10}$ the observed SERS spectrum is a multivariate function of factors, including shape, size, proximity and extent of plasmon coupling between the neighboring nanoparticles, and the nature of the molecules adsorbed or coordinated on the metal surface. In addition, it is necessary to distinguish between the selection rules for vibrational transitions of a molecule in the gas phase (where infrared and Raman activities are easily determined from the symmetry point group) and the surface selection rules that should be used in the case of spatially oriented molecules at the surface of nanoparticles. ${ }^{28}$ Surface selection rules encompass the symmetry properties of the dipole transitions and the modification of the intensities due to coupling with components of the local electric field vector at the surface. They apply to molecules anchored on nanostructures where Raman and infrared intensities are further modulated by the spatial resolution of the local electric field interacting with the polarizability tensor. Since the adsorbed molecule generally belongs to a symmetry point group distinct from that of the parent free molecule, the corresponding allowed vibrational modes and their polarization are also different.
All the factors influencing the intensity of the plasmon field and the optical extinction spectra of the nanoparticles are very important for understanding the SERS behavior of the adsorbed molecules. As a matter of fact, extremely high electric fields can occur at the surface of plasmonic metals in some discontinuity points, such as nanoholes or corrugated structures at the nanoscale. Such intense electric fields are known as "hot spots" and respond, at least in part, for the SERS effect observed for organic molecules adsorbed onto copper, gold and silver electrodes. ${ }^{29,30}$

In the case of the plasmonic nanoparticles, it has been shown that "hot spots" are naturally generated in the aggregation process, which enhances the plasmon coupling interactions. Theoretical studies ${ }^{31}$ support the conclusion that the "hot spots" are localized in the region between two interacting nanoparticles where the electric field is strongly intensified under the influence of the longitudinal plasmon resonance, which, on the other hand, is responsible for the red shifted coupling band. The electric field in the "hot spot" region depends on the direction of the electric dipole vector of the electromagnetic radiation relative to the interparticle axis, reaching the maximum when the polarization vector is parallel to this axis (Figure 4). ${ }^{31}$

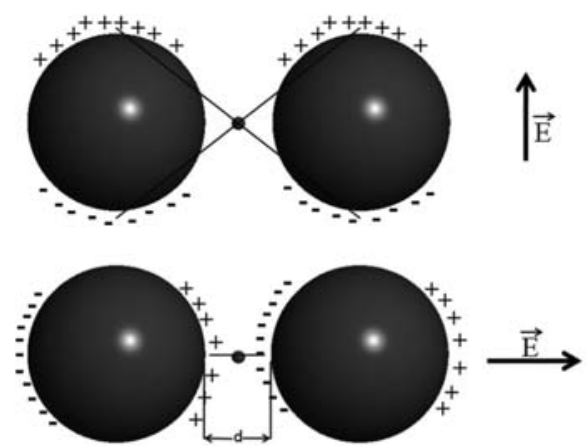

Figure 4. Molecules located within the interparticle region experience a much intense electric field when the axis of the oscillating electric dipole of the incident light coincides with that of the longitudinal plasmon resonance.

Another important aspect is that the metal-adsorbate structure permits new excitations, such as the chargetransfer $(\mathrm{CT})$ transitions from the Fermi level $\left(\mathrm{E}_{\mathrm{F}}\right)$ to the lowest unnoccupied molecular orbitals of the molecule $\left(\mathrm{E}_{\mathrm{F}} \rightarrow \mathrm{LUMO}\right)$ or from the highest occupied molecular orbital to $\mathrm{E}_{\mathrm{F}}\left(\mathrm{HOMO} \rightarrow \mathrm{E}_{\mathrm{F}}\right)$. When the excitation is in resonance with the electronic transition in the metaladsorbate complex, the surface-enhanced Raman scattering can also incorporate this type of metal-molecule chargetransfer mechanism, as originally proposed by Otto et al..$^{32}$ Usually, the Fermi level for metals (e.g., $-4.3 \mathrm{eV}$ for $\mathrm{Ag}$ ) lies above the HOMO of most molecules (e.g., $-9.26 \mathrm{eV}$ for pyridine), and lower than their LUMO level. Thus, 
for every $\mathrm{HOMO} \rightarrow$ LUMO transition there should be a corresponding Fermi level charge-transfer transition $\left(\mathrm{E}_{\mathrm{F}} \rightarrow \mathrm{LUMO}\right.$ or $\left.\mathrm{HOMO} \rightarrow \mathrm{E}_{\mathrm{F}}\right)$, which is lower in energy than the purely molecular transition. For this reason, it tends to contribute more to the SERS intensity using visible excitation radiation. Although the $\mathrm{E}_{\mathrm{F}} \rightarrow \mathrm{LUMO}$ or $\mathrm{HOMO} \rightarrow \mathrm{E}_{\mathrm{F}}$ transitions are not usually observed using conventional spectrophotometry, they can be predicted in terms of the semi-classical electron transfer theories recently proposed by Creutz, Brunschwig and Sutin. ${ }^{33}$

Resonance Raman (RR) involving the electronic levels of the adsorbed molecules is also very important. This possibility is also referred as SERRS, or surface-enhanced resonance Raman scattering, and the observed spectral intensities may be quite different from those found in the original Raman spectrum of the parent molecules.

Recently, a unified view of surface-enhanced Raman scattering has been presented by Lombardi and Birke ${ }^{34}$ in terms of the contributions of $i$ ) the electromagnetic (EM) surface plasmon resonance in the metal nanoparticle, ii) the charge-transfer (CT) resonance at the metal-molecule interface and iii) the resonances (RR) within the molecule itself. It extends the Albrecht ${ }^{35}$ formalism to the moleculemetal system, including the Herzberg-Teller coupling between the filled and unfilled levels. Accordingly, the following expression has been proposed (equation 10).

$$
R_{I F K}(\omega)=\frac{\mu_{K I} \mu_{F K} h_{I F}\left\langle i\left|Q_{k}\right| f\right\rangle}{\left[\left(\varepsilon_{1}(\omega)+2 \varepsilon_{m}\right)^{2}+\varepsilon_{2}^{2}\right]\left(\omega_{F K}^{2}-\omega^{2}+\gamma_{F K}^{2}\right)\left(\omega_{I K}^{2}-\omega^{2}+\gamma_{I K}^{2}\right)}
$$

The surface enhanced Raman intensity is proportional to the square of the polarizability, or $\left|\mathrm{R}_{\mathrm{IFK}}(\omega)\right|^{2}$, where I, F and $\mathrm{K}$ refer to the ground state, a charge-transfer state and an excited molecular state of the molecule-metal system, respectively ${ }^{34}$ The denominator of equation 10 involves the product of three terms, each of which represents a specific contribution to SERS. The first term, $\left[\varepsilon_{1}(\omega)-2 \varepsilon_{\mathrm{m}}\right]^{2}+\varepsilon_{2}^{2}$, describes the contribution of the electromagnetic plasmon resonance at $\varepsilon_{1}(\omega)=-2 \varepsilon_{\mathrm{m}}$ (EM mechanism) The second term, $\left(\omega_{\mathrm{FK}}{ }^{2}-\omega^{2}+\gamma_{\mathrm{FK}}{ }^{2}\right)$, involves the Fermi energy dependent charge-transfer state $(\mathrm{F})$, and promotes a chargetransfer resonance at $\omega=\omega_{\mathrm{FK}}(\mathrm{CT}$ mechanism). The third term, $\left(\omega_{\mathrm{IK}}{ }^{2}-\omega^{2}+\gamma_{\mathrm{IK}}{ }^{2}\right)$, involves the ground and excited states of the molecule, and leads to the molecular resonance at $\omega=\omega_{\mathrm{IK}}$ (RR mechanism). Therefore, equation 10 predicts the possibility of one, two or three resonances, depending on the metal and adsorbed molecule characteristics, as well as on the excitation wavelength, oscillator strength and bandwidth, Fermi energy, and size and shape of the nanoparticles.
Accordingly, the numerator of equation 10 provides the selection rules for SERS, since it involves the transition moments for the molecular transition, $\mu_{\mathrm{KI}}$, and for the metalmolecule charge transfer transition, $\mu_{\mathrm{FK}}$, and also includes the Herzberg-Teller term $h_{\mathrm{IF}}=\langle\mathrm{I}|\partial \mathrm{V} / \partial \mathrm{Q}| \mathrm{F}\rangle$ multiplied by the vibrational integral $\left\langle i\left|\mathrm{Q}_{k}\right| \mathrm{f}\right\rangle$. All four terms must be nonzero for a particular vibrational mode be observed. However, it should be noted that all four terms are linked to each other. Even when there is no molecular resonance excited in a particular region, the intensity can be borrowed from the molecular transitions via Herzberg-Teller coupling mechanism. ${ }^{34}$

The charge-transfer transition moment $\left(\mu_{\mathrm{FK}}\right)$ is coupled to the component of the electric field due to the surface plasmon resonance perpendicular to the surface. Therefore, charge-transfer (CT) and surface plasmon (EM) are intimately coupled to each other, and it is important to know the orientation of the molecule with respect to the surface. On the other hand, the charge-transfer (CT) resonance is linked to the molecular resonance (RR) by the transition moment $\mu_{\mathrm{KI}}$ since they both refer to the same excited state $\mathrm{K}$. The Herzberg-Teller coupling constant, $\mathrm{h}_{\mathrm{IF}}$, provides the link between the charge-transfer state $(\mathrm{F})$ and the Raman signals governed by $\left\langle i\left|\mathrm{Q}_{\mathrm{k}}\right| \mathrm{f}\right\rangle$. Therefore, the three resonances (EM, CT, RR) contributing to SERS intensities should be considered simultaneously. Presumably, all three resonances contribute to the huge enhancements up to 14 orders of magnitude observed in the SERS spectra of single molecules, as observed by $\mathrm{Xu}^{36}$ and Michaels. ${ }^{37}$

\section{Stability of Gold Nanoparticles Dispersions}

Colloidal dispersions can be described by the Derjarguin-Laudau-Verwey-Overbeck (DLVO) theory, ${ }^{38}$ normally expressed in terms of the balance between the attractive van der Waals forces and the repulsive Coulomb forces, screened by the Debye-Hückel factor. According to this theory, the total interaction potential between two gold nanoparticles $\left(\mathrm{V}_{\mathrm{T}}\right)$ is given by the sum of electrostatic repulsion $\left(\mathrm{V}_{\text {elec }}\right)$ and the van der Waals attraction $\left(\mathrm{V}_{\mathrm{vdw}}\right)$ terms,

$V_{T}=V_{\text {elec }}+V_{v d w}$

Depending on the particles size and the double layer thickness, the electrostatic repulsion potential, $\mathrm{V}_{\text {elec }}$, between two nanoparticles of radii $R_{1}$ and $R_{2}$ can be expressed by

$V_{\text {elec }}=4 \pi \varepsilon \psi_{0}^{2} \frac{R_{1} R_{2}}{\left(R_{1}+R_{2}\right)} \ln [1+\exp (-\kappa x)]$

(in the case of $\kappa R>5$ ) 
or

$$
V_{\text {elec }}=4 \pi \varepsilon R_{1} R_{2} Y_{1} Y_{2}\left(\frac{k_{B} T}{e}\right)^{2} \frac{\exp (-\kappa x)}{x+R_{1}+R_{2}}
$$

(in the case of $\kappa R<5$ )

where

$\kappa=\left[\frac{1000 e^{2} N_{A}(2 I)}{\varepsilon k_{B} T}\right]^{1 / 2}$

$Y_{i}=\frac{8 \tanh \left(e \psi_{o} /\left(4 k_{B} T\right)\right)}{1+\left[1-\frac{2 \kappa R_{i}+1}{\left(\kappa R_{i}+1\right)^{2}} \tanh ^{2}\left(e \psi_{o} /\left(4 k_{B} T\right)\right)\right]^{1 / 2}}$

and $\varepsilon$ is the dielectric constant of the medium, $\psi_{\mathrm{o}}$ the potential at the particle surface, $\kappa$ is the Debye factor, $\mathrm{x}$ is the distance of closest approach between two colloidal particle surfaces, e the electronic charge, $\mathrm{k}_{\mathrm{B}}$ the Boltzmann constant, $\mathrm{T}$ the temperature, $\mathrm{N}_{\mathrm{A}}$ the Avogadro number, and I is the ionic strength of the medium.

The van der Waals attraction potential, $\mathrm{V}_{\mathrm{vdw}}$, can be calculated as

$V_{\text {vdw }}=-\frac{A_{H}}{6}\left[\frac{2 R_{1} R_{2}}{d^{2}-\left(R_{1}+R_{2}\right)^{2}}+\frac{2 R_{1} R_{2}}{d^{2}-\left(R_{1}-R_{2}\right)^{2}}-\ln \frac{d^{2}-\left(R_{1}+R_{2}\right)^{2}}{d^{2}-\left(R_{1}-R_{2}\right)^{2}}\right]$

where $\mathrm{d}$ is the center-to-center separation distance, and $\mathrm{A}_{\mathrm{H}}$ is the Hamaker constant, estimated as $2.5 \times 10^{-19} \mathrm{~J}$.

In the case of nanoparticles coated with surfactants and polymers, repulsive forces can also arise from the balance of the overlapping long chain capping materials and their interactions with the surrounding solvent molecules. This effect is also referred as osmotic repulsion, $\mathrm{V}_{\text {osm }}$, because it can be modeled in terms of the volume fraction occupied by the capping molecules and the molecular volume of the solvent. As a matter of fact, alkane thiols have been extensively employed for the functionalization of gold nanoparticles because of their favorable metal-ligand affinity and the influence of the hydrocarbon chains on interparticle repulsion potentials. ${ }^{14}$ Organothiols have also been modified with suitable functional groups in order to impart molecular recognition properties ${ }^{14,39}$ or to generate interesting building blocks for constructing supramolecular structures. ${ }^{40}$

\section{Ligand Substitution and Agglomeration of Gold Nanoparticles}

The properties of gold nanoparticles are associated with the large percentage of surface atoms and their delocalized electrons which behave as plasmon waves. The coordination sites of the surface atoms are not complete, allowing the binding of donor-acceptor species, or ligands. Although systematic studies on the coordination chemistry of metal nanoparticles are yet rather scarce, the known affinity of gold nanoparticles by thiol ligands suggests a great similarity with the corresponding metal ion chemistry. Thus, the application of hard and soft acid-base concepts can be very helpful for understanding the coordination chemistry of gold nanoparticles.

In solution, ligand exchange at the surface of gold nanoparticles should take place in a way similar to the observed for the corresponding metal ion complexes, although specific rate constants are yet missing from the literature. The reason is that, in addition to the metal-ligand affinities, the kinetic description should also incorporate the relevant aspects of colloidal chemistry that control the stabilization and occurrence of flocculation of nanoparticles in solution, leading sometimes to the formation of longlived metastable clusters. ${ }^{41}$ In this sense, it is pertinent to adopt the terminology employed by Whitesides et al. ${ }^{42}$ using generically the term "flocculation" to refer to the instability of colloidal dispersions, and keeping the term "agglomeration" for the cases involving loose, reversible association of nanoparticles, and "aggregation" for close, irreversible association. ${ }^{4} \mathrm{~A}$ general behavior observed for citrate stabilized gold nanoparticles, cit-AuNPs, involves a rapid ligand exchange at the surface followed by a slower flocculation process responsible for the rise of a plasmon coupling band above $700 \mathrm{~nm}$. Depending on the concentration and ionic strength, a third, irreversible process involving aggregation or precipitation can be observed, leading to a general decay of the absorption bands.

The kinetics of interaction of citrate stabilized gold nanoparticles, cit-AuNPs, with the negatively charged ligand 3-mercapto-1-propane sulfonate (mps) and the positively charged 2-mercaptoethylammonium (mea) has been investigated by Bellino et al. ${ }^{44}$ by monitoring the changes in the electronic spectra as a function of time (Figure 5). These two systems exhibited a rather distinct behavior.

In the case of the mea ligand, present in high excess, the kinetics proceeded very fast, according to a second power of the relative absorbance changes $\left(\Delta \mathrm{A}_{\mathrm{r}}\right)^{2} v s$. time. A faster reaction is indeed expected based on the favorable electrostatic interaction of the positively charged mea and negatively charged cit-AuNPs. The rate-determining step is the agglomeration of the modified nanoparticles, justifying the approximate second order behavior observed experimentally. In the case of the negatively charged mps, the kinetics was rather slow and compatible with the following equation

$$
\frac{\mathrm{d} A}{\mathrm{~d} t}=-k C^{\frac{1}{2}} \Delta A_{r}\left(1-\Delta A_{r}\right) \exp \left(-b \Delta A_{r}\right)
$$




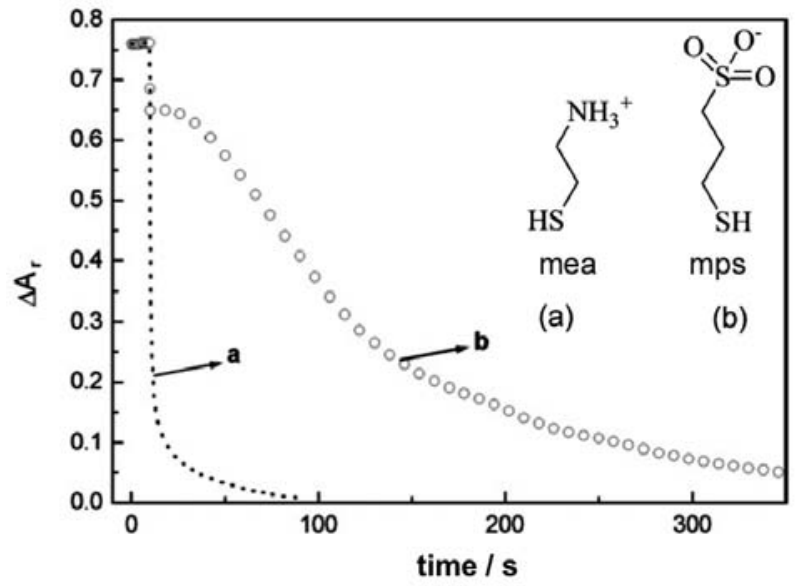

Figure 5. Relative changes in the plasmon band intensities $\left(\Delta \mathrm{A}_{\mathrm{r}}\right)$ of cit-AuNPs as a function of time, for positively and negatively charged ligands, mea (a) and mps (b).

where $\mathrm{k}$ is the apparent rate constant, $\mathrm{C}$ is the concentration of the thiol ligand, and $b$ is an empirical constant. Because of the unfavorable electrostatic repulsion, the rate determining step in this case is the adsorption, or ligand exchange process. The kinetic complexity is related to the gradual exchange of the citrate by the mps ligand, modifying the nanoparticles zeta potential along the time. The initial repulsion is responsible for an induction period. As the ligand exchange proceeds, the repulsion becomes smaller, accelerating the kinetics up to reaction completion. The exponential term in equation 17 was associated with the electrostatic work necessary to approximate the negatively charged species.

The binding of neutral species such as 2- and 4-mercaptopyridine (2-mpy and 4-mpy, respectively) to cit-AuNPs has been investigated in our laboratory. ${ }^{45}$ In both cases, the kinetics proceeds relatively fast, leading to the decay of the $520 \mathrm{~nm}$ band and to the rise of the plasmon coupling band at $650 \mathrm{~nm}$, characteristic of flocculation. The corresponding kinetic plots are shown in Figure 6. The observed profiles are consistent with a very fast ligand exchange process $\left(\mathrm{t}_{1 / 2}<10 \mathrm{~s}\right)$ followed by a slower agglomeration process, similar to the behavior reported by Bellino et al. $^{44}$ for a positively charged ligand.

11-Mercaptoundecanoic acid (mua) has also been employed in the stabilization of gold nanoparticles. The coordination to cit-AuNP surface occurs via the thiolate group, such that the carboxylate group can play the role of increasing the electrostatic repulsion, thus preventing flocculation. It has been shown that metal ions such as $\mathrm{Cd}^{2+}$, $\mathrm{Hg}^{2+}$ and $\mathrm{Pb}^{2+}$ interact with the carboxylate groups, inducing the agglomeration of the nanoparticles. This process can be monitored by the changes in the plasmon resonance bands in the visible. ${ }^{46}$ The effect can be reversed by the addition
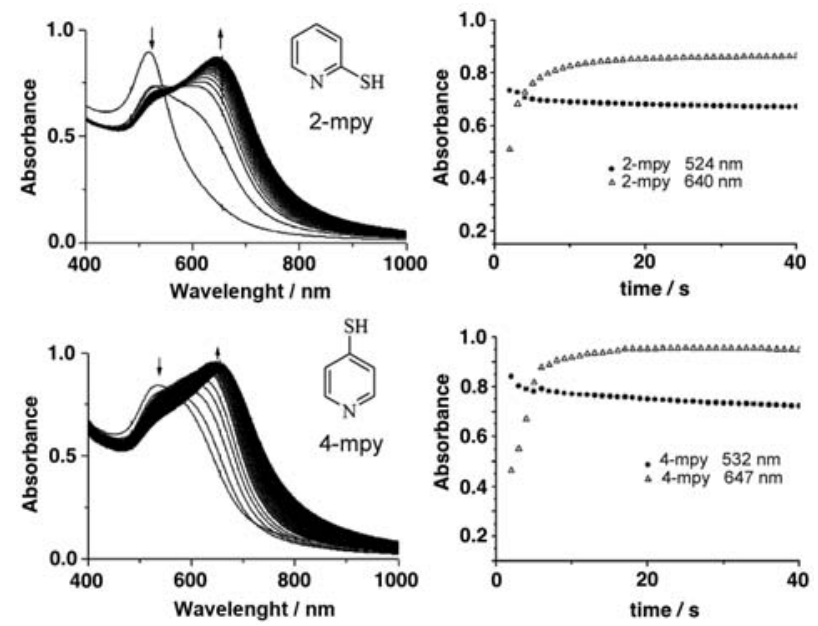

Figure 6. Successive spectra of cit-AuNPs recorded after the addition of $5 \times 10^{-6} \mathrm{~mol} \mathrm{dm}^{-3} 2$-mpy and 4-mpy (time interval = $120 \mathrm{~s}$ ). (Adapted from reference 56).

of edta, which coordinates those heavy metal ions strongly and displaces them from the AuNP surface.

Gold nanoparticles modified with a 15 -crown-5 ether bearing an anchoring thiol group agglomerate in the presence of potassium ions due to the formation of 2:1 complexes. Based on the red to blue color changes associated with the plasmon coupling band, potassium can be detected at concentrations between $7.6 \mu \mathrm{mol} \mathrm{dm}{ }^{-3}$ and $0.48 \mathrm{mmol} \mathrm{dm}^{-3} .{ }^{47}$

Another interesting aspect is the possibility to control the stabilization/destabilization of AuNP dispersions by exploiting the selective binding of charged metal complexes. Pentacyanoferrate(II) ions are unique candidates for this purpose, because of their high negative charges and suitable substitution reaction kinetics and thermodynamic behavior. Such species have been extensively used to probe the binding affinity of specific donor atoms towards iron. ${ }^{48-52}$ This is justified, since the cyanides in the $\left[\mathrm{Fe}(\mathrm{CN})_{5}\right]^{3-}$ group are inert, leaving only one coordination site for interaction with a specific donor atom of a multifunctional ligand (L). On the other hand, the chemical properties of the resultant $\left[\mathrm{Fe}(\mathrm{CN})_{5} \mathrm{~L}\right]^{3-}$ complexes are strongly dependent on the nature of L. For instance, pentacyanoferrate(II) ions show a high affinity for $N$-heterocyclic ligands, aminoacids and $S$-donor ligands such as sulfoxides, ${ }^{52}$ thioethers ${ }^{48}$ and thioamides. ${ }^{53}$ Interestingly, the affinity of the pentacyanoferrate(II) ions for thiol groups is relatively small ${ }^{45}$ in contrast to their high affinity for strong $\pi$-acceptor ligands such as pyridine and pyrazine. ${ }^{50,51}$

In this way, an interesting result has been obtained by replacing the 2- and 4-mercaptopyridine ligands by their corresponding pentacyanoferrate(II) complexes. ${ }^{45}$ In the case of the $\left[\mathrm{Fe}(\mathrm{CN})_{5}(2-\mathrm{mpy})\right]^{3-}$, flocculation takes place rapidly, as observed for free 2-mpy. Coordination in this 
case takes place preferentially at the $\mathrm{C}=\mathrm{S}$ thione bond of 2-mpy, rather than to the $\mathrm{N}$ atom, for steric reasons. In addition, $\left[\mathrm{Fe}(\mathrm{CN})_{5}(2-\mathrm{mpy})\right]^{3-}$ is relatively labile and coexists in equilibrium with free 2 -mpy $\left(\mathrm{K}_{\mathrm{f}}=1.5 \times 10^{4} \mathrm{~mol}\right.$ $\left.\mathrm{dm}^{-3}\right)$. Its dissociation $\left(\mathrm{k}_{\mathrm{d}}=1.7 \times 10^{-2} \mathrm{~s}^{-1}\right)$ releases 2 -mpy, which is rapidly scavenged by the gold nanoparticles, inducing their flocculation (Figure 7). It should be noted that, in this case, both $\left[\mathrm{Fe}(\mathrm{CN})_{5}\right]^{3-}$ and gold atoms compete for the sulfur atoms of the 2-mpy ligand. The formation of the 2-mpy-AuNPs becomes the driving force for inducing the complete dissociation of the $\left[\mathrm{Fe}(\mathrm{CN})_{5}(2-\mathrm{mpy})\right]^{3-}$ complex.

In contrast, for the $\left[\mathrm{Fe}(\mathrm{CN})_{5}(4-\mathrm{mpy})\right]^{3-}$ isomer, the iron(II) ion coordinates preferentially to the pyridine $N$-atom, leaving the thiol group completely free to bind to the surface of gold nanoparticles. In addition, this complex is more stable $\left(\mathrm{K}_{\mathrm{f}}=2.6 \times 10^{5} \mathrm{~mol} \mathrm{dm}^{-3}\right)$ and inert $\left(\mathrm{k}_{\mathrm{d}}=1.1 \times 10^{-3} \mathrm{~s}^{-1}\right) \cdot{ }^{30,45}$ As a matter of fact, when $\left[\mathrm{Fe}(\mathrm{CN})_{5}(4-\mathrm{mpy})\right]^{3-}$ is added to citrate AuNPs, no evidence of flocculation has been observed. The complex strongly binds to AuNPs through the thiol group, increasing the negative charge on the surface and the electrostatic potential of the functionalized nanoparticles, further stabilizing the dispersion. In this case, flocculation can be induced only by drastically increasing the ionic strength, for instance using concentrated solutions of $\mathrm{NaCl}$.

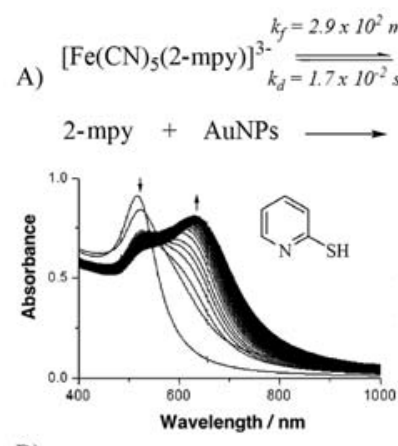

B)

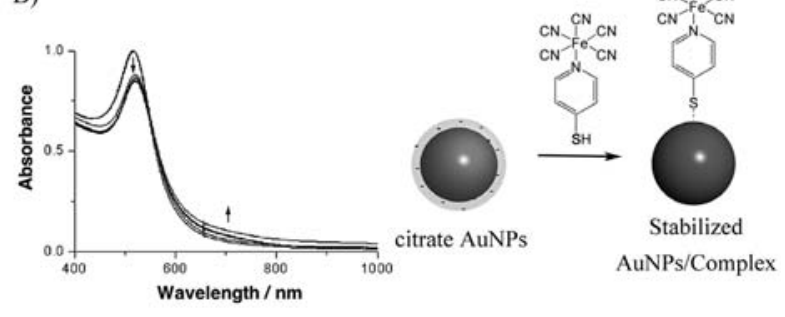

Figure 7. Ligand exchange reactions of citrate $\mathrm{AuNPs}$ and $(\mathrm{A})\left[\mathrm{Fe}(\mathrm{CN})_{5}\right.$ (2-mpy) $]^{3-}$, leading to aggregation, as monitored by the plasmon resonance $(525 \mathrm{~nm})$ and plasmon coupling bands $(634 \mathrm{~nm})$; and $(\mathrm{B})\left[\mathrm{Fe}(\mathrm{CN})_{5}\right.$ (4-mpy) $]^{3-}$, leading to stabilized nanoparticles (adapted from reference 45 ).

Another interesting system is provided by the pyrazine-2-ethanethiol (pzt) ligand. ${ }^{54}$ In this case, there is a preferential binding of the $\left[\mathrm{Fe}(\mathrm{CN})_{5}\right]^{3-}$ complex to the pyrazine moiety, leaving the $\mathrm{SH}$ group available for interacting with the gold nanoparticles, as illustrated in Figure 8.

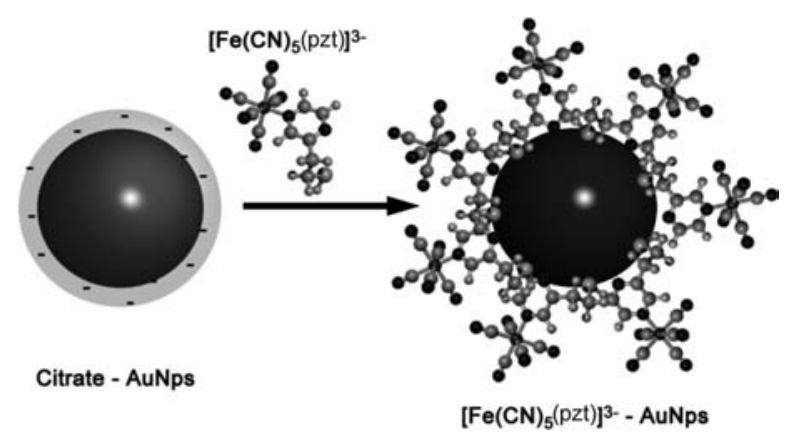

Figure 8. Representation of a gold nanoparticles stabilized with $\left[\mathrm{Fe}(\mathrm{CN})_{5}(\mathrm{pzt})\right]^{3-}$ complexes.

The electronic configuration of the $\left[\mathrm{Fe}(\mathrm{CN})_{5}(\mathrm{pzt})\right]^{3-}$ complex is typically low spin, as a consequence of the strong ligand field provided by the cyanide ligands. The UV-Vis spectrum exhibits two characteristic, strong absorption bands at $\lambda_{\max }=266 \mathrm{~nm}$ and $461 \mathrm{~nm}$ ( $\log \varepsilon=3.68)$, ascribed to pzt intraligand $\pi-\pi^{*}$ transition, and to metal-to-ligand charge transfer (MLCT) transition, i.e., $d_{\pi}\left(\mathrm{Fe}^{\mathrm{II}}\right) \rightarrow p_{\pi^{*}}(\mathrm{pzt})$, respectively, by analogy with the literature..$^{50}$ The spectral variation of the gold nanoparticles in the presence of pzt $\left(1 \times 10^{-5} \mathrm{~mol} \mathrm{dm}^{-3}\right)$ can be seen in Figure 9. After the addition of pzt to the gold nanoparticles solution, the intensity of the plasmon absorption band at $520 \mathrm{~nm}$ decreases in parallel with the rise of a new band above $600 \mathrm{~nm}$. As this band becomes more intense, there is a bathochromic shift to $660 \mathrm{~nm}$. Such optical changes can be ascribed to aggregation of the gold nanoparticles, which arises from the mutual interference of the plasmon levels in neighboring nanoparticles. The intensity of the $660 \mathrm{~nm}$ band reaches a maximum, after which there is gradual decay and shift to about $700 \mathrm{~nm}$ due to the precipitation process.

A contrasting behavior is observed for the $\left[\mathrm{Fe}(\mathrm{CN})_{5}(\mathrm{pzt})\right]^{3-}$ modified AuNps. In Figure 10, the spectra of the AuNps upon addition of $\left[\mathrm{Fe}(\mathrm{CN})_{5}(\mathrm{pzt})\right]^{3-}\left(1 \times 10^{-5} \mathrm{~mol} \mathrm{dm}^{-3}\right)$ are shown. The characteristic MLCT band at $460 \mathrm{~nm}$ for the $\left[\mathrm{Fe}(\mathrm{CN})_{5}(\mathrm{pzt})\right]^{3-}$ complex can be observed as a shoulder of the plasmon resonance band at $520 \mathrm{~nm}$, exhibiting only a small decrease in intensity after the binding and replacement of the citrate shell of the gold nanoparticles. In this case, similarly to the $\left[\mathrm{Fe}(\mathrm{CN})_{5}(4-\mathrm{mpy})\right]^{3-}$ complex, a stable colloidal solution is formed, remaining unchanged for many days under argon.

An interesting experiment has been carried out, aiming at the removal of the $\left[\mathrm{Fe}(\mathrm{CN})_{5}\right]^{3-}$ ion from $\left[\mathrm{Fe}(\mathrm{CN})_{5}(\mathrm{pzt})\right]-$ AuNP using dimethyl sulfoxide (dmso), Figure 11. 

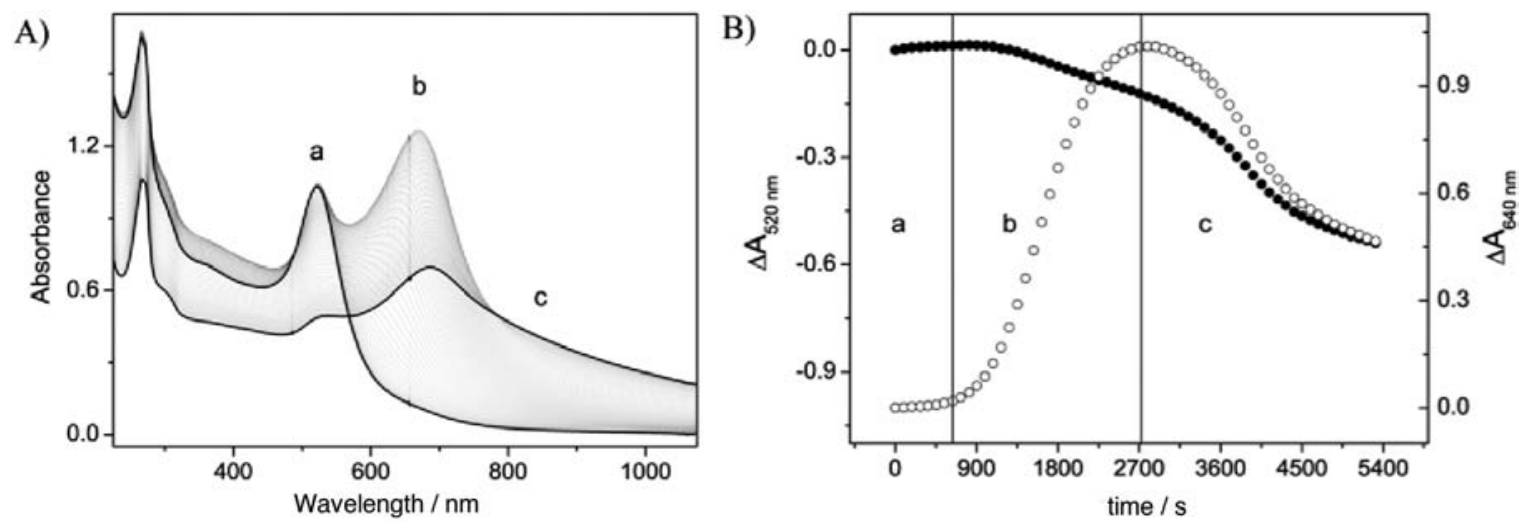

Figure 9. Changes of the UV-Vis spectra of cit-AuNps upon addition of pzt $\left.\left(1 \times 10^{-5} \mathrm{~mol} \mathrm{dm}^{-3}\right) \mathrm{A}\right)$ as a function of time and B) as function of individual $(520 \mathrm{~nm})$ and coupled plasmon bands $(640 \mathrm{~nm})$; (a) ligand exchange reaction $(\mathrm{t}=0 \mathrm{~min})$, (b) flocculation $(\mathrm{t}=42 \mathrm{~min}),(\mathrm{c})$ precipitation $(\mathrm{t}=90 \mathrm{~min})$ (adapted from reference 54).

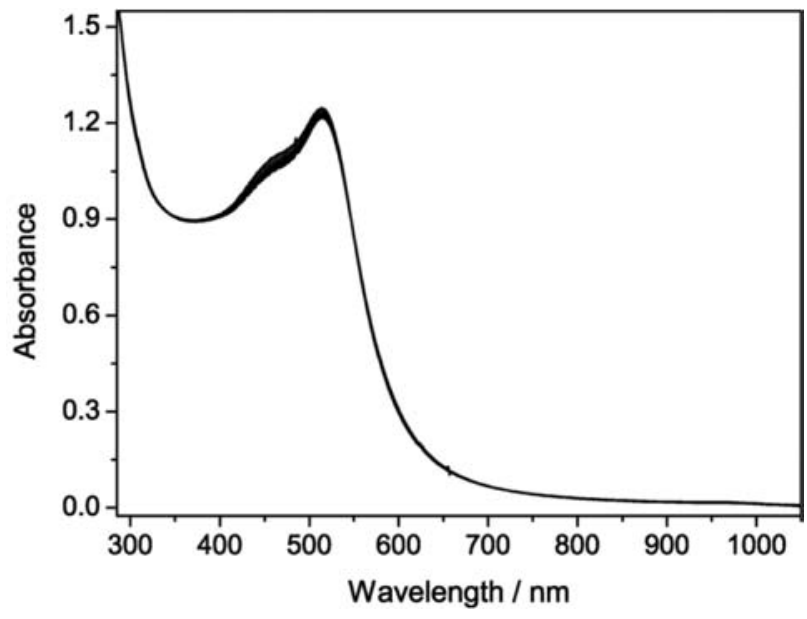

Figure 10. Successive UV-Vis spectra of AuNps showing only a very small decrease in intensity after addition of $1 \times 10^{-5} \mathrm{~mol} \mathrm{dm}^{-3}\left[\mathrm{Fe}(\mathrm{CN})_{5}(\mathrm{pzt})\right]^{3-}$ $(\mathrm{t}=90 \mathrm{~min})$. Adapted from reference 54 .

Dimethyl sulfoxide is a good scavenger for $\left[\mathrm{Fe}(\mathrm{CN})_{5}\right]^{3-}$ ions, ${ }^{52}$ yielding the very stable and inert $\left[\mathrm{Fe}(\mathrm{CN})_{5}(\mathrm{dmso})\right]^{3-}$ complex, which does not absorb in the visible region. The substitution kinetics of the pzt ligand in the $\left[\mathrm{Fe}(\mathrm{CN})_{5}(\mathrm{pzt})\right]^{3-}$ complex proceeds by a dissociative mechanism, ${ }^{49,50}$ which can be expressed by the reactions

$$
\begin{aligned}
& {\left[\mathrm{Fe}(\mathrm{CN})_{5}(\mathrm{pzt})\right]^{3-} \underset{k_{\text {ppt }}}{\frac{k_{p t}}{\longrightarrow}}\left[\mathrm{Fe}(\mathrm{CN})_{5}\right]^{3-}+\mathrm{pzt}} \\
& {\left[\mathrm{Fe}(\mathrm{CN})_{5}\right]^{3-}+\mathrm{H}_{2} \mathrm{O} \stackrel{k_{-1}}{\underset{k_{l}}{\longrightarrow}}\left[\mathrm{Fe}(\mathrm{CN})_{5}\left(\mathrm{H}_{2} \mathrm{O}\right)\right]^{3-}} \\
& {\left[\mathrm{Fe}(\mathrm{CN})_{5}\right]^{3-}+\mathrm{dmso} \stackrel{k_{\text {dmso }}}{\longrightarrow}\left[\mathrm{Fe}(\mathrm{CN})_{5}(\mathrm{dmso})\right]^{3-}}
\end{aligned}
$$

As previously shown, ${ }^{49,50}$ under pseudo first order conditions and assuming a steady-state hypothesis for the $\left[\mathrm{Fe}(\mathrm{CN})_{5}\right]^{3-}$ intermediate, the observed rate constants are given by

$$
k_{o b s}=\frac{k_{-p z t} k_{d m s o}[d m s o]}{k_{p z t}[p z t]+k_{d m s o}[d m s o]}
$$

In the presence of a large excess of dmso, $k_{d m s o}[d m s o]>>$ $k_{p z t}[p z t]$, and the observed rate constant coincides with the limiting dissociation rate constant for the $\left[\mathrm{Fe}(\mathrm{CN})_{5}(\mathrm{pzt})\right]^{3-}$ complex, i.e., $k_{o b s=} k_{-p z i}$

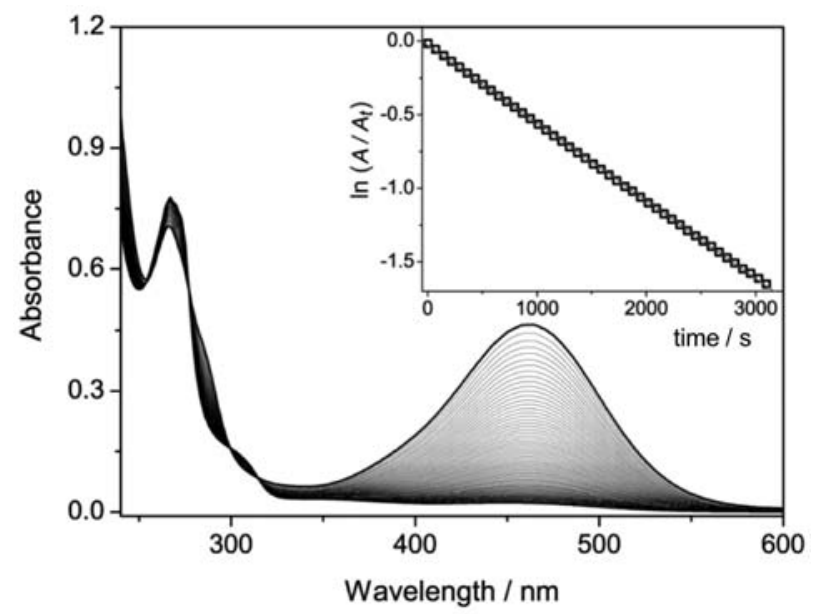

Figure 11. UV-Vis spectra of $1 \times 10^{-4} \mathrm{~mol} \mathrm{dm}^{-3}\left[\mathrm{Fe}(\mathrm{CN})_{5}(\mathrm{pzt})\right]^{3-}$ in the presence of $0.5 \mathrm{~mol} \mathrm{dm}^{-3} \mathrm{dmso}$. Inset: first order kinetic plot, where $k_{o b s}=5.2 \times 10^{-4} \mathrm{~s}^{-1}$ (adapted from reference 54$)$.

The same pattern has also been observed (Figure 12) for the $\left[\mathrm{Fe}(\mathrm{CN})_{5}(\mathrm{pzt})\right]^{3-}$ stabilized gold nanoparticles in the presence of dmso $\left(0.5 \mathrm{~mol} \mathrm{dm}^{-3}\right)$. Analogously to the free complex, the reaction with dmso leads to an exponential decrease of the MLCT band at $c a .460 \mathrm{~nm}$ (Figure 12, inset), with a kinetic dissociation constant of $6.2 \times 10^{-4} \mathrm{~s}^{-1}$. This value is comparable to $5.2 \times 10^{-4} \mathrm{~s}^{-1}$ obtained for the free complex.

It should be noted that the dissociation of the pentacyanoferrate(II) complex from the AuNps surface removes the negative charges responsible for the 
electrostatic potential that stabilizes the nanoparticles suspension. Therefore, as expected, the ligand substitution reaction is followed by the flocculation of the resulting pzt-AuNps, leading to an increase of the absorbance at $640 \mathrm{~nm}$, as shown in Figure 12. The kinetics involves two separate steps, i.e.,

$\left[\mathrm{Fe}(\mathrm{CN})_{5}(\mathrm{pzt})\right]^{3-}-\mathrm{AuNps}+\mathrm{dmso} \rightarrow\left[\mathrm{Fe}(\mathrm{CN})_{5}(\mathrm{dmso})\right]^{3-}+$ pzt-AuNps

pzt-AuNps $\rightarrow$ flocculation.

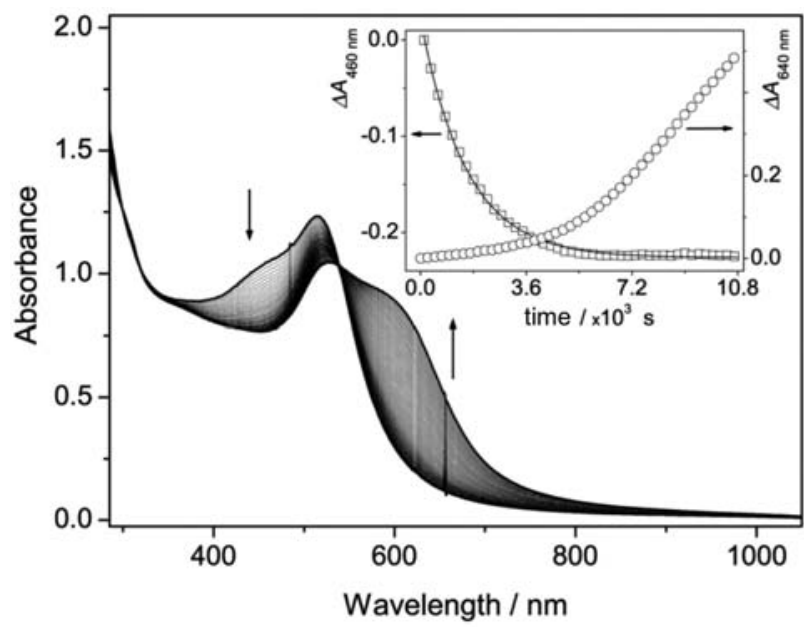

Figure 12. UV-Vis spectra and dissociation kinetics of the $\left[\mathrm{Fe}(\mathrm{CN})_{5}(\mathrm{pzt})\right]^{3-}$ stabilized gold nanoparticles after addition of $0.5 \mathrm{~mol} \mathrm{dm}^{-3} \mathrm{dmso}$. Inset: Decrease of absorbance at 460 ( $\square$ - left) and $640 \mathrm{~nm}$ ( $\bigcirc$ - right). The solid line is a pseudo-first order behavior fit at $460 \mathrm{~nm}$, where $k_{o b s}=6.2 \times 10^{-4} \mathrm{~s}^{-1}$ (Adapted from reference 54).

These examples illustrate how the coordination chemistry at the surface and the ligand exchange kinetics can be used to control the stabilization of nanoparticles and to induce aggregation processes.

\section{SERS Spectra of Metal Complexes-Nano- particles Interfaces}

The occurrence of SERS in the aggregated pzt-AuNps is illustrated in Figure 13, in comparison with the normal Raman spectra of pzt (pure form).

Because of the very low concentration $\left([\mathrm{pzt}]=10^{-5} \mathrm{~mol} \mathrm{dm}^{-3}\right)$ employed in the measurements, the strong (SERS) intensification of the pzt vibrational peaks is quite evident in Figure 13. In the case of the pzt-AuNps, the aggregation phenomenon in aqueous solution leads to the rise of a plasmon coupling band around $660 \mathrm{~nm}$. Excitation at the $785 \mathrm{~nm}$ laser wavelength results in the selective enhancement of the vibrational modes associated with the pzt ligand, involving both the pyrazine ring and alkanethiol

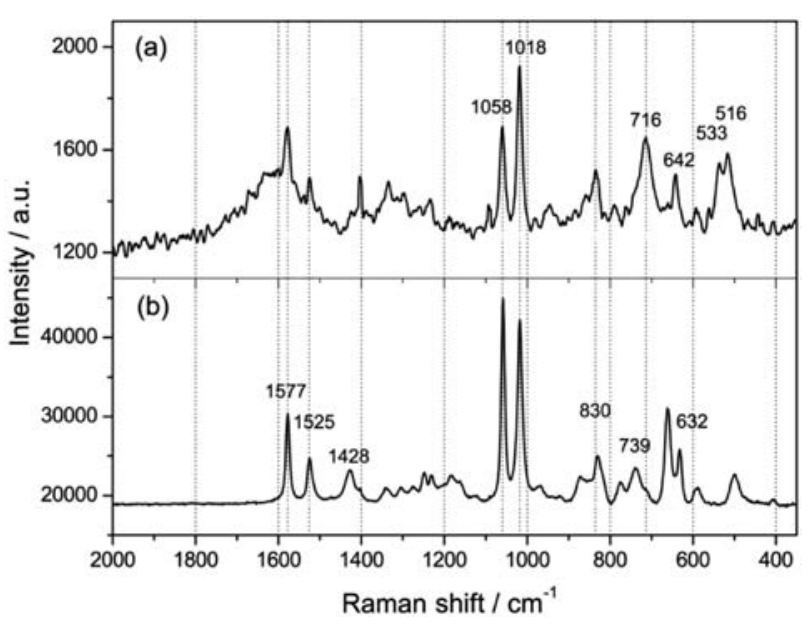

Figure 13. SERS spectrum $\left(\lambda_{\text {exc }}=785 \mathrm{~nm}\right)$ of the pzt-AuNps $([\mathrm{pzt}]=$ $1 \times 10^{-5} \mathrm{~mol} \mathrm{dm}^{-3}$ ) (a) and Raman spectrum of pzt in pure liquid form (b) (Adapted from reference 54).

moieties. ${ }^{54}$ It is interesting to note in Figure 13 that the relative intensity of the peaks at 1058 and $1018 \mathrm{~cm}^{-1}$, which are associated with ethanethiol and pyrazine vibrational modes, respectively, is inverted in relation to the normal Raman spectrum of the pzt species. The peaks at $c a .738$ and $500 \mathrm{~cm}^{-1}$, ascribed to $\mathrm{C}-\mathrm{S}$ stretching and $\mathrm{CH}_{2}-\mathrm{CH}_{2}$ vibrational modes, undergo strong enhancement and shift to 716 and $516 \mathrm{~cm}^{-1}$ respectively. Because of the matching of the plasmon coupling and laser frequencies, the EM mechanism of intensification seems rather plausible in this case.

For the pentacyanoiron stabilized AuNPs, strong SERS effect has been observed as shown in Figure 14, in spite of the lack of agglomeration and absence of the plasmon coupling band above $600 \mathrm{~nm}$. The $659 \mathrm{~cm}^{-1}$ peak ascribed to the C-S stretching mode exhibited the greatest

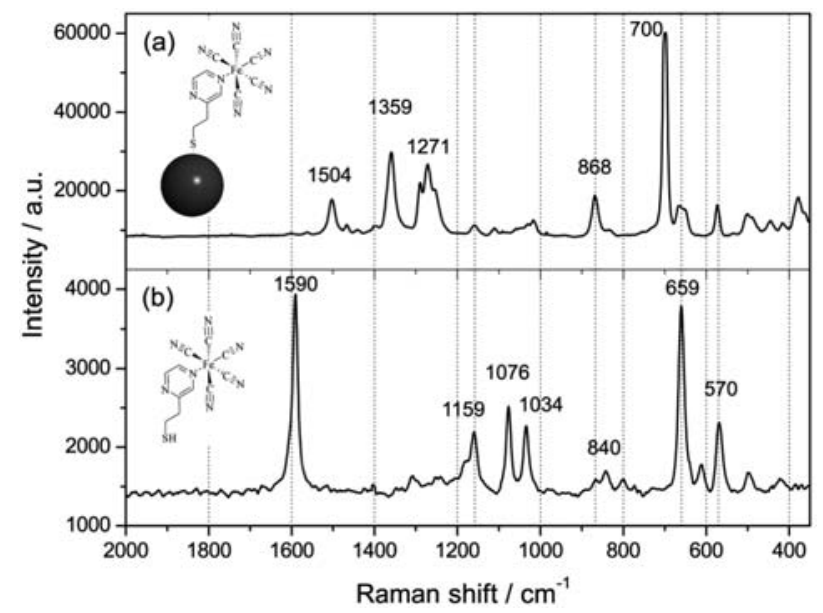

Figure 14. SERS spectrum $\left(\lambda_{\text {exc }}=785 \mathrm{~nm}\right)$ of the $\mathrm{Na}_{3}\left[\mathrm{Fe}(\mathrm{CN})_{5}(\mathrm{pzt})\right]$ complex at $10^{-5} \mathrm{~mol} \mathrm{dm}^{-3}$ bound to AuNps (a) and normal Raman spectrum of the iron complex at $1 \mathrm{~mol} \mathrm{dm}^{-3}$ aqueous solution (b) (Adapted from reference 54). 
enhancement, shifting to $700 \mathrm{~cm}^{-1}$. The original peaks at 1590, 1159, 1076 and $1034 \mathrm{~cm}^{-1}$ in the normal spectra practically vanish and some new peaks appear in this region. This result suggests a different origin for the SERS effect in the $\left[\mathrm{Fe}(\mathrm{CN})_{5}(\mathrm{pzt})\right]^{3-}$ stabilized AuNps, in comparison with the pzt-AuNps aggregates. The enhancement of the new bands seems to be associated with the electronic character of the excited state, and the occurrence of a charge-transfer mechanism and/or molecular resonance mechanism of intensification seems rather plausible in this case.

It should be noticed that optical electron transfer from an occupied molecular orbital of the adsorbate to the Fermi level can actually take place under laser excitation at a more favored condition, because of the stronger laser light intensity. Such transition would hardly be detected in conventional optical measurements. Indirect evidence for this type of mechanism has already been reported for the $\left[\left\{\mathrm{Fe}(\mathrm{CN})_{5}\right\}_{2}(\mu \text {-bipy })\right]^{6-}$ complex adsorbed on a silver electrode ${ }^{55}$ where the Fermi energy levels were modulated according to the applied potentials. Although direct spectroscopic evidence has not been obtained for this type of system, it is important to notice that outer-sphere chargetransfer excitation in pentacyanoferrate(II) complexes has already been reported in the literature, ${ }^{56}$ as well as in $\mathrm{TiO}_{2}$ films containing anchored $\left[\mathrm{Fe}(\mathrm{CN})_{5} \mathrm{~L}\right]^{\mathrm{n}-}$ species. ${ }^{57}$

Another interesting work deals with the coordination properties of the trithiocyanuric acid or 2,4,6-trimercapto1,3,5-triazine (tmt) at gold nanoparticles. The tmt is a small, symmetric molecule, displaying three $\mathrm{N}$ atoms and three thiol grupos available for binding metal ions. This species has been extensively employed for removing hazardous heavy metal ions from industrial wastewaters and polluted waters. ${ }^{58,59} \mathrm{In}$ aqueous solution, tmt undergoes three successive acid-base dissociation reactions for which the corresponding equilibrium constants have already been determined ${ }^{58}$ as $\mathrm{pK}_{\mathrm{a} 1}=5.71 ; \mathrm{pK}_{\mathrm{a} 2}=8.36$ and $\mathrm{pK}_{\mathrm{a} 3}=11.38$. The free molecule admits several tautomeric forms involving the thiol to thione conversion. The tmt vibrational spectra have already been investigated, and the assignments are supported by theoretical calculations. For this reason, tmt does provide a suitable molecular probe for the investigation of the SERS effect on gold nanoparticles.

It has been reported that when cit-AuNPs $(25 \mathrm{~nm}$, $\left.7 \times 10^{-10} \mathrm{~mol} \mathrm{dm}^{-3}\right)$ are mixed with tmt $\left(1.7 \times 10^{-6} \mathrm{~mol} \mathrm{dm}^{-3}\right)$, there is a shift of the localized plasmon resonance band from 522 to $528 \mathrm{~nm}$, and an increase of the average size distribution from 25 to $30 \mathrm{~nm} .{ }^{60}$ However, no evidence of agglomeration has been observed in the electronic spectrum and the dynamic light scattering (DLS) profiles were consistent with stable suspensions, showing that tmt is a good stabilizing agent for gold nanoparticles in aqueous solution. Because of its multiple binding sites, tmt interacts very strongly with the citrate stabilized gold nanoparticles, displacing the citrate ions.

Flocculation of the tmt modified gold nanoparticles, tmt-AuNPs, can be induced by adding electrolytes such as $\mathrm{NaCl}$ in order to change the ionic strength. As shown in Figure 15, the addition of $0.04 \mathrm{~mol} \mathrm{dm}^{-3} \mathrm{NaCl}$ promotes the immediate flocculation of the tmt-AuNPs, leading to a partial decay of the plasmon band at $528 \mathrm{~nm}$ and rise of a broad plasmon coupling band at $700 \mathrm{~nm}$, which reaches a steady state at $733 \mathrm{~nm}$ in few seconds. At a longer time scale, there is a general decay of all absorption bands, due to the precipitation of the aggregates. In fact, after the flocculation step the process becomes completely irreversible.

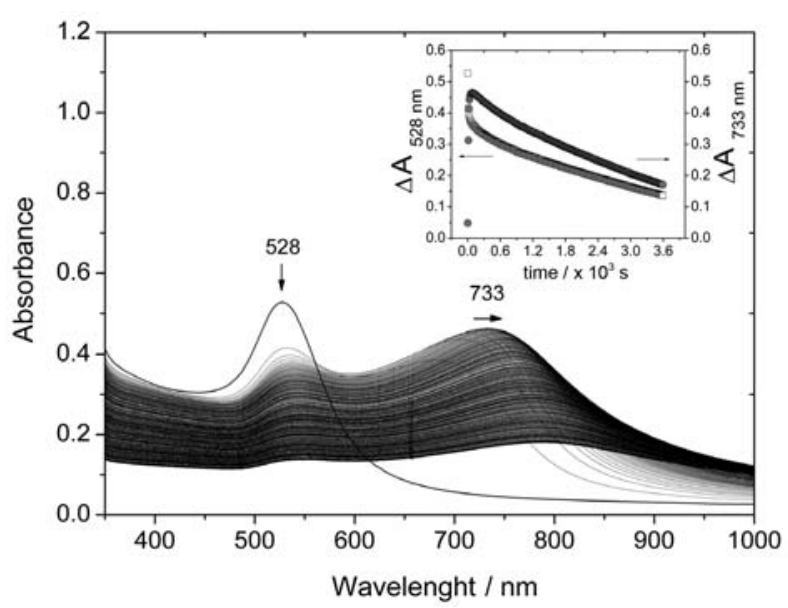

Figure 15. Absorption spectra of a tmt-AuNP aqueous suspension showing the plasmon band at $528 \mathrm{~nm}$, and successive spectral changes measured at $10 \mathrm{~s}$ intervals in the presence of $0.1 \mathrm{~mol} \mathrm{dm}^{-3} \mathrm{NaCl}$. Inset: time variation profiles at 528 and $733 \mathrm{~nm}$ (Adapted from reference 60).

The precipitation process can be delayed by keeping the extent of flocculation very small, just enough to obtain a detectable plasmon coupling band and a reasonably intense Raman spectra. This has been done empirically by using $0.004 \mathrm{~mol} \mathrm{dm}^{-3} \mathrm{NaCl}$, as shown in Figure 16. In this case, there was a small increase of absorption associated with the plasmon coupling band above $700 \mathrm{~nm}$, which remained quite stable for very long periods of time. Such small absorption was enough to produce a rather strong and reproducible SERS spectrum associated with the agglomerated tmt-AuNPs.

The spectral stability obtained under such conditions seems to be ideal for analytical purposes, but most important is the fact that at this low flocculation level the system remained quite active chemically. In this way, strong, reproducible SERS signals were obtained for the tmt-AuNPs showing the characteristic tmt vibrational peaks modified by the interaction with the gold nanoparticles 


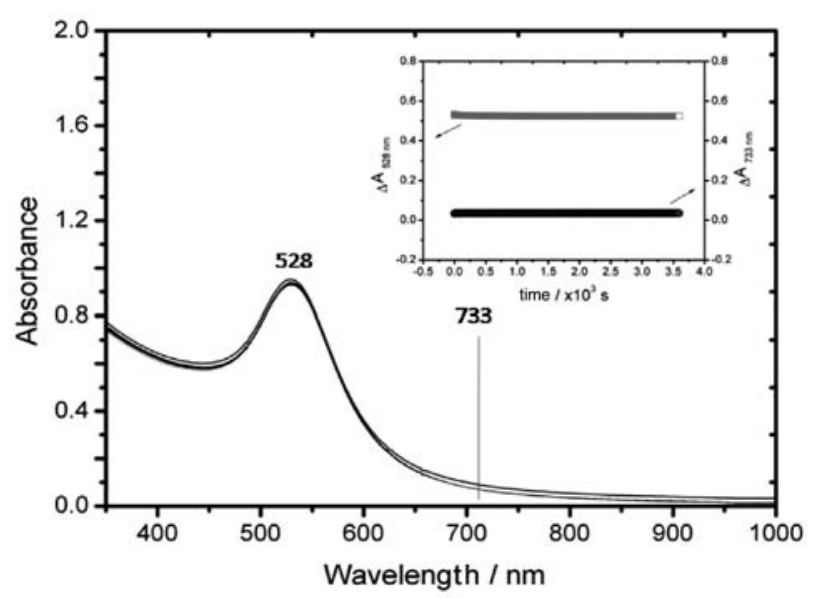

Figure 16. Spectrum of a tmt-AuNP suspension before and after the addition of $0.01 \mathrm{~mol} \mathrm{dm}^{-3}$ of $\mathrm{NaCl}$, showing the rise of a small absorption due to the plasmon coupling band at $733 \mathrm{~nm}$. Inset: time profiles following the variation of absorbance at 528 and $733 \mathrm{~nm}$ (Adapted from reference 60).

surface. The most strongly enhanced peaks were associated with vibrational modes exhibiting major contributions from the C-S and S-H groups, e.g., at 1259, 897, 872, 485 and $432 \mathrm{~cm}^{-1}$, except for the peaks at 1218 and $971 \mathrm{~cm}^{-1}$, which are associated with ring vibrations. This result is consistent with tmt bound to the gold nanoparticles surface through the $\mathrm{S}$ and the heterocyclic $\mathrm{N}$ atoms. Because of the symmetry and close proximity of the thiol and nitrogen binding sites, a tridentate coordination mode has been proposed for the interaction of tmt with AuNP (Figure 17). In this way, the third sulfur and the two vicinal heterocyclic $N$-atoms remain available for interacting with metal ions at the tmt/ solution interface.

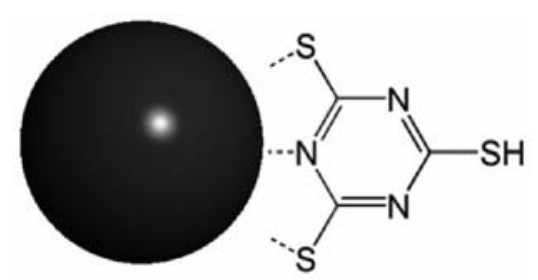

Figure 17. Illustration of the proposed binding mode for tmt-AuNP.

Since tmt is a good complexing ligand, many successful experiments have been carried out using tmt-AuNP as SERS probes for detecting metal ions such as $\mathrm{Hg}^{2+}$ and $\mathrm{Cd}^{2+}$. Typical SERS spectra recorded after the addition of $\mathrm{Hg}^{2+}$, at $\mathrm{pH} 4$, can be seen in Figure 18. There is a systematic decrease of the $v(\mathrm{C}-\mathrm{S})$ peaks at 485 and $432 \mathrm{~cm}^{-1}$ as the $\mathrm{Hg}^{2+}$ ion concentration is increased in the $2 \times 10^{-7}$ to $2 \times 10^{-6} \mathrm{~mol} \mathrm{dm}^{-3}$ range, consistent with the strong binding of the metal ion to the thiol groups. Concomitantly, there is a gradual increase of the $\beta_{\text {ring }}$ peak at $973 \mathrm{~cm}^{-1}$ suggesting the involvement of the heterocyclic $N$-atom in a bidentate coordination mode to the $\mathrm{Hg}^{2+}$ ion, as illustrated in Figure 20.

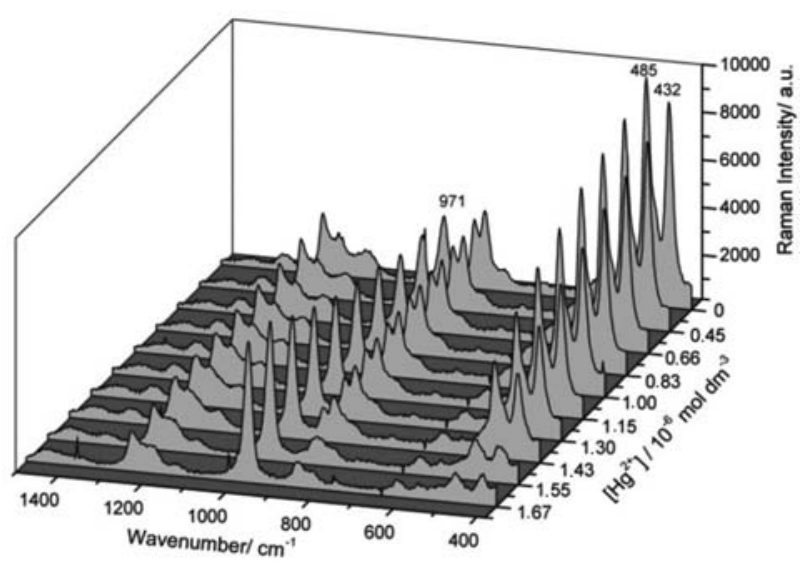

Figure 18. SERS spectral profiles for tmt-AuNP aqueous suspension ( $\mathrm{pH} 4.4$ ), recorded at several concentrations of $\mathrm{Hg}^{2+}$ ions (Adapted from reference 60 ).

In contrast, the addition of $\mathrm{Cd}^{2+}\left(2.5 \times 10^{-7}\right.$ to $3 \times 10^{-6} \mathrm{~mol} \mathrm{dm}^{-3}$ range) to the tmt-AuNPs solution promoted a strong enhancement of the ring vibrational peak at $971 \mathrm{~cm}^{-1}$, while the C-S stretching modes at 485 and $432 \mathrm{~cm}^{-1}$ exhibited only a small decay as a function of $\mathrm{Cd}^{2+}$ concentration, as shown in Figure 19. Accordingly, this metal ion should be interacting primarily with the ring $N$-atoms. However, a bidentate coordination seems also rather plausible due to the proximity of the sulfur atom (as illustrated in Figure 20a), but involving a weaker $\mathrm{Cd}^{2+}-\mathrm{S}$ bond.

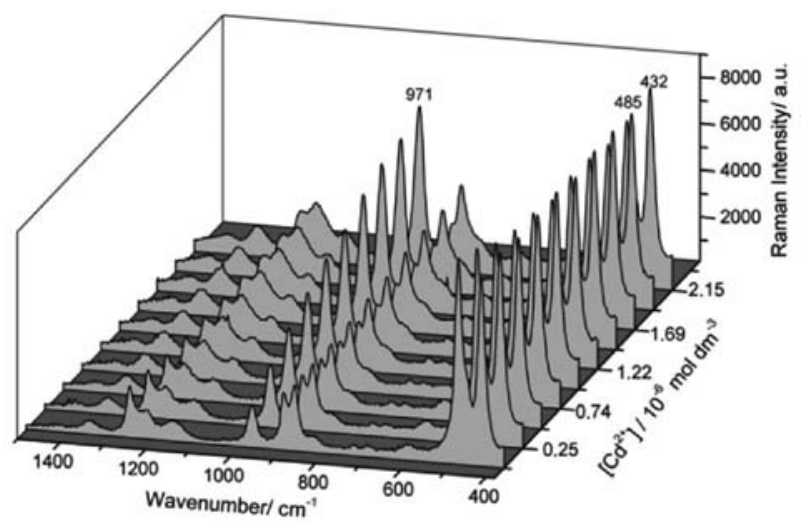

Figure 19. SERS spectral profiles for tmt-AuNP solution ( $\mathrm{pH} 4.4)$, in the presence of increasing concentrations of $\mathrm{Cd}^{2+}$ ion (Adapted from reference 60 ).

Calibration curves can be obtained by plotting the peak intensities versus concentration. However, an interesting point to be noted in Figure 18 is the multiple trends in the peak intensities, such as those at 971 and 485 or $432 \mathrm{~cm}^{-1}$, as a function of the $\mathrm{Hg}^{2+}$ concentration. In fact, based on the linear correlation found for the ratio of the intensities of the peaks at 432 and $971 \mathrm{~cm}^{-1}$ or 485 and $971 \mathrm{~cm}^{-1}$ versus the concentration of $\mathrm{Hg}^{2+}$ (Figure 21), a very convenient analytical strategy has been proposed. ${ }^{60}$ Note 

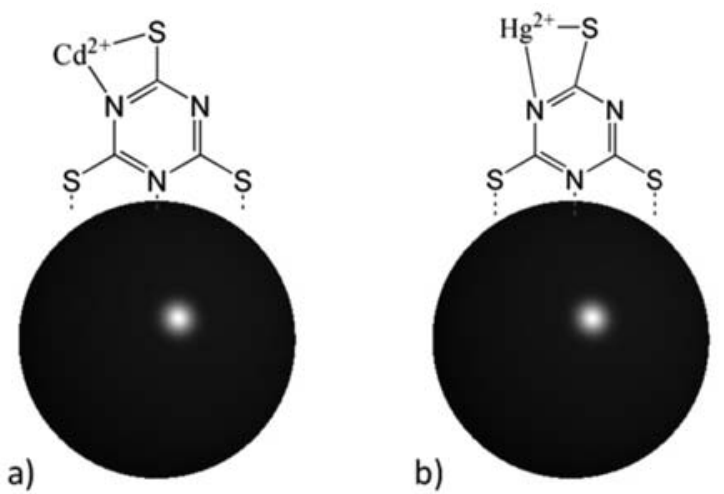

Figure 20. Illustration of the binding modes of (a) $\mathrm{Cd}^{2+}$ and (b) $\mathrm{Hg}^{2+}$ ions to tmt-AuNP.

that the tmt ligand acts as a molecular probe and an internal reference, eliminating the problems associated with the low reproducibility of the SERS probes. Accordingly, the use of the relative peak intensity ratios is a straightforward procedure, eliminating most of the concerns of making absolute measurements under variable conditions, such as the need of introducing internal standards as in most of the spectroscopic methods. The linear correlation was better than 0.99 and the slopes reflected good accuracy and sensitivity for the analytical method, such that the limit was found to be in the ppb range. Similar good analytical results have been obtained for $\mathrm{Cd}^{2+}$ as can be seen in Figure 21. Furthermore, the distinct spectral behavior shown in Figures 18 and 19 allows the unambiguous identification of the analytes.

\section{Assembling Coordination Compounds at Gold Nanoparticles Surface}

Gold nanoparticles, in addition to their plasmon resonance and SERS effects, can also be employed for assembling supramolecular structures ${ }^{61}$ by anchoring metal complexes on their surfaces. Such heterohybrid supramolecular species ${ }^{40}$ are of great importance, since they encompass the relevant chemical properties of the metal complexes under the influence of the nanoparticle core and of the surface plasmons, allowing interesting applications in molecular recognition, energy/electron transfer and catalysis. ${ }^{4}$

A close parallelism between gold nanoparticles and gold electrodes arises from the previous studies involving the binding of coordination compounds and ligands such as 4-mpy to corrugated gold surfaces. ${ }^{8,29,30,62}$ For instance, Moreira and coworkers ${ }^{29,30,63}$ investigated the adsorption of the $\left[\mathrm{M}(\mathrm{CN})_{5}(4-\mathrm{mpy})\right]^{\mathrm{n}-}$ complex $\left(\mathrm{M}=\mathrm{Fe}^{\mathrm{II}}, \mathrm{Ru}^{\mathrm{II}}\right)$ on gold, silver and copper electrode surfaces using surface enhanced Raman spectroscopy. They reported significant
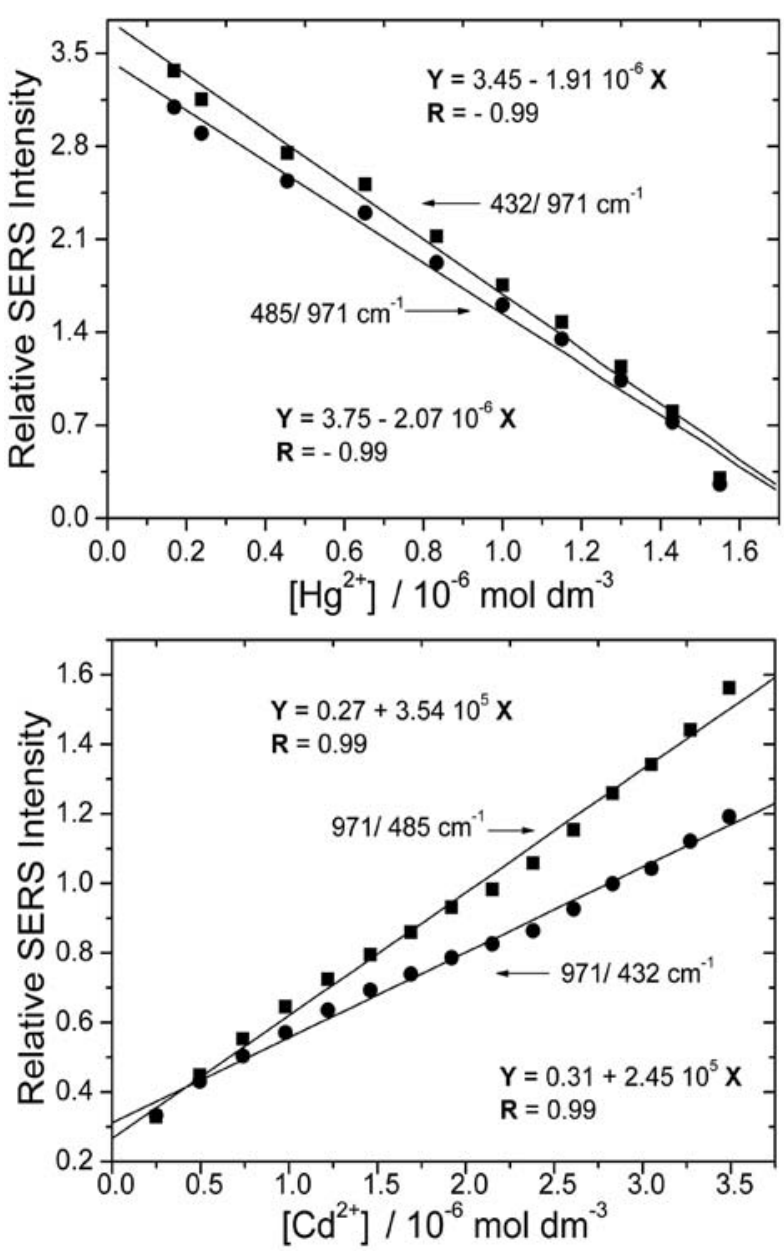

Figure 21. Plots of the relative intensity of the peaks at 432 and $971 \mathrm{~cm}^{-1}$, and at 485 and $971 \mathrm{~cm}^{-1}$, versus the concentration of $\mathrm{Hg}^{2+}(\mathrm{A})$; and plots of the relative intensity of the peaks at 971 and $485 \mathrm{~cm}^{-1}$, and at 971 and $432 \mathrm{~cm}^{-1}$, versus the concentration of $\mathrm{Cd}^{2+}(\mathrm{B})$. Adapted from reference 60 .

changes in the relative intensities of the vibrational modes of pyS and $\mathrm{CN}$ ligands, reflecting the occurrence of chemical interactions involving both ligands and the metal surface. The ability to determine the orientation of the adsorbed complexes permitted to control the properties of the interface, as demonstrated by the study of the electrochemistry of cytochrome-c (cyt-c) on surfaces prepared by different methods. A reversible electrochemical response of the metalloprotein was only observed on the self-assembled surfaces where the $\mathrm{CN}$ moieties were available to interact with the protein molecule.

Wang and $\operatorname{Sin}^{64}$ have reported the functionalization of gold nanoparticles with $\gamma$-mercaptopropionic acid in order to coat the surface with catalytically active ruthenium carbonyl complexes, as illustrated in Figure 22.

Knight et al. ${ }^{65}$ have recently employed the zwitterionic piperazine dithiocarbamate, $\mathrm{S}_{2} \mathrm{CNC}_{4} \mathrm{H}_{8} \mathrm{NH}_{2}$, to bind transition metal complexes to gold nanoparticles, as illustrated in Figure 23. 


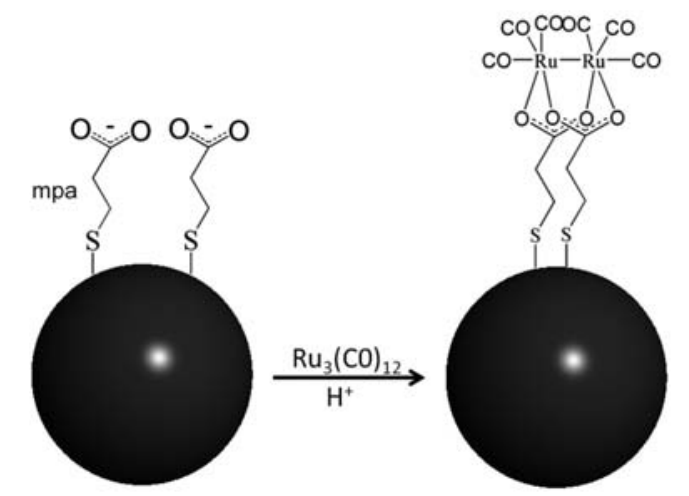

Figure 22. Coating gold nanoparticles with Ru carbonyl mercaptopropanoate complexes.

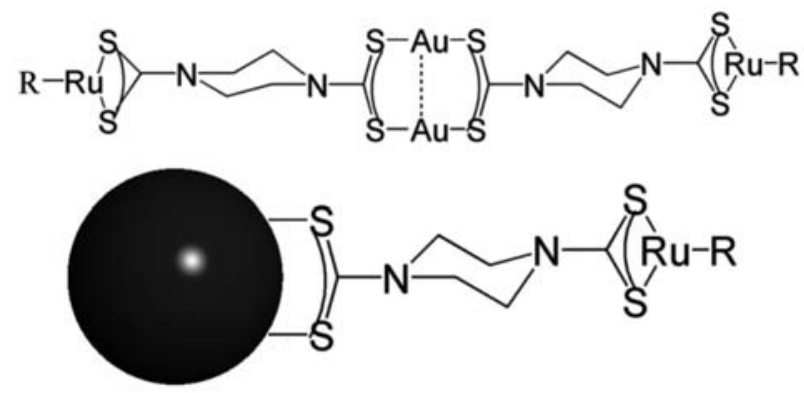

Figure 23. Anchoring ruthenium complexes to gold nanoparticles via the piperazine dithiocarbamate ligand.

Ferrocene has also been anchored on gold nanoparticles through the previous binding of mercaptoacetate followed by the condensation of ethylenediamine- $N$-ferrocenylamide with the existing carboxylic groups. The modified nanoparticles self-aggregate yielding micro and nanometric spheres, depending on their concentration. ${ }^{66,67}$ This ferrocene amide derivative anchored on gold nanoparticles exhibited an unusual electrochemical behavior in the presence of dihydrogen phosphate anion. The redox peaks of the ferrocene moieties decreased in intensity and a new, less positive pair of peaks appeared, allowing the detection of the dihydrogen phosphate anion. Hydrogen bonds between the amide groups and the negatively charged oxyanions were probably responsible for this effect. ${ }^{67}$ Astruc and coworkers have also anchored two types of dendronized thiol ligands containing nonasilylferrocenyl and amidoferrocenyl groups to gold nanoparticles, and observed a shift of the redox peaks of ferrocene in the presence of dihydrogen phosphate anion and ATP. ${ }^{68}$ Recently, Angelici and Lazar reported the binding of isocyanides to gold metal surfaces, aiming at applications in catalysis, nanochemistry and molecular electronics. ${ }^{69}$ Costa et $a l .{ }^{70}$ reported the use of high performance gold nanorods and silver nanocubes in surface-enhanced Raman spectroscopy of pesticides. Ruthenium polypyridine complexes have also been anchored to gold nanoparticles by Mayer et $a .^{71}$ as shown in Figure 24, allowing the exploration of their chemical, electrochemical and photochemical properties.

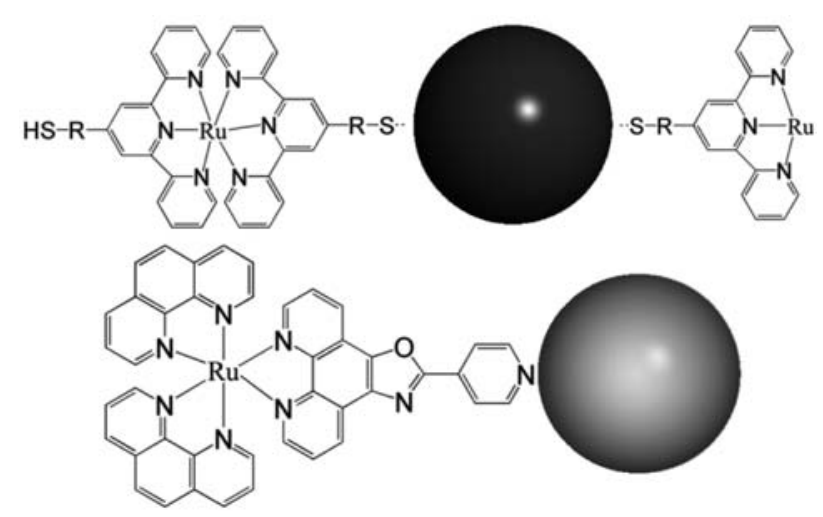

Figure 24. Ruthenium complexes immobilized onto plasmon nanoparticles.

Dong et $a l .^{72}$ have reported the immobilization of ruthenium terpyridine complexes at gold nanoparticles, and exploited their use in modified electrodes. A chiral rhodiumdiphosphine complex anchored on gold nanoparticles has been successfully employed for asymmetric catalysis, leading to a full conversion and $93 \%$ yield in terms of enantiomeric excess, comparable to the free catalyst, in the hydrogenation of methyl $\alpha$-acetamidocinnamate. ${ }^{73}$ Similarly, a titanium(IV) bisnaphtol isopropoxide complex (Figure 25) has been employed by Marubayashi et al..$^{74}$ as an AuNP modifier, exhibiting a very high activity in the asymmetric alkylation of benzaldehyde, with enantiomeric excess superior to $80 \%$. This catalyst has also the advantage of being easier to recuperate and purify.

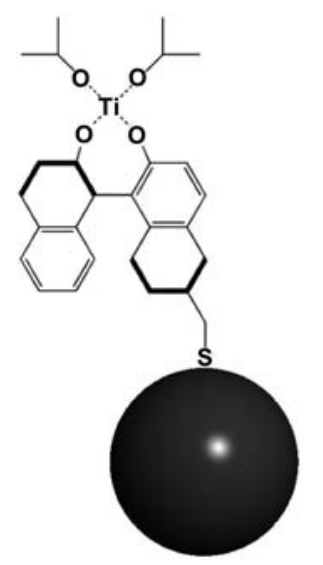

Figure 25. An enantioselective catalyst based on AuNP capped with a titanium(IV) bisnaphtol complex.

Gadolinium has been anchored on gold nanoparticles using a derivative of diethylenetriaminepentaacetic acid condensed with 1,2-mercaptoamine. Each gold nanoparticle 
can immobilize about 150 gadolinium complex molecules, improving the sensitivity of magnetic resonance imaging by exhibiting a much higher relaxativity as compared with the free complexes. ${ }^{75}$

An interesting application of metal complexes is as fluorescent probes in association with gold nanoparticles. According to Thomas et al. ${ }^{76}$ the luminescence of metal complexes at gold nanoparticles is susceptible to energy transfer from one site to the other, or quenching by the nanoparticle surface by means of energy or electron transfer, as illustrated in Figure 26.
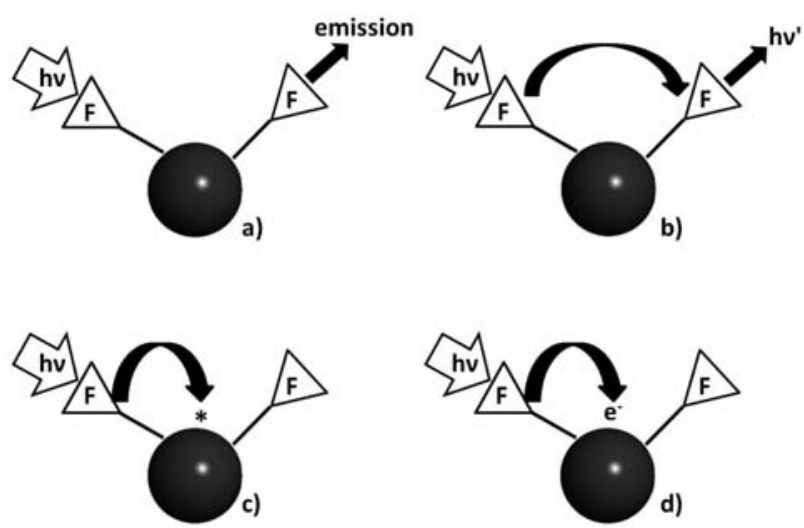

Figure 26. Schemes showing the influence of AuNP in the a) throughparticle and b) intersite energy transfer; and quenching by c) energy and b) electron transfer pathways in a metal complex-gold nanoparticle system.

Pramod et al. ${ }^{77}$ have investigated the photochemical behavior of the $\left[\mathrm{Ru}(\text { bipy })_{3}\right]^{2+}$ complex $^{78}$ at the surface of gold nanoparticles, showing the formation of $\left[\mathrm{Ru}(\mathrm{bipy})_{3}\right]^{+}$ species in photoinduced electron transfer processes. Murray et al..$^{75,79}$ investigated the interaction of $\left[\mathrm{Ru}(\text { bipy })_{3}\right]^{2+}$ and thiopronin at gold nanoparticles surface, showing the quenching of the complex luminescence by this species via energy transfer.

Gold nanoparticles capped with monothiolated bipy derivatives can bind europium(III) and terbium(III) ions forming self-assembled complexes. Red and green luminescences have been observed for europium and terbium ions, respectively, with quantum yields greater than those given by similar complexes formed from cryptand or calixarene derivatives containing bipyridyl moieties. The luminescence decreased dramatically in the presence of calcium(II), magnesium(II), zinc(II), nickel(II) and copper(II) ions, allowing interesting applications as metal sensors. ${ }^{75}$

Another interesting example has been described by Hallet et al.,$^{80}$ employing gold nanoparticles of small size $(3.6 \mathrm{~nm})$ coated with luminescent rhenium complexes. Surprisingly, the luminescence of the complexes was not quenched by the nanoparticles, due to the shift of the plasmon resonance to high energies as a consequence of the nanoparticles small size, thus mismatching the complex charge transfer bands. The large energy separation between the complex acceptor levels (located at the bipyridine ligands) and the nanoparticle Fermi level can also be a relevant point.

Interestingly, gold nanoparticles can also undergo photophysical and photochemical changes, including morphological modifications, under laser irradiation. ${ }^{81}$ As a matter of fact, intense pulse lasers with various energies and wavelengths have been used to prepare gold nanostructures, and to reshape gold nanorods into nanospheres. The photon energy absorbed by the conduction band electrons is transferred to the nanoparticles lattice and in this way the electron-phonon is converted into heat. The hot gold nanoparticles can release photofragments and also part of the molecular coating, but, as the heat diffuses into the solution, the fragments undergo recombination. This process, repeated at every successive laser pulse, leads to an increase in the nanoparticle size. The final result is similar to a photoinduced fusion process and can be readily monitored by the changes in the plasmon resonance bands. An interesting example has been described by Bonifácio et al..$^{82}$ involving citrate stabilized gold nanoparticles anchored on hydrotalcite particles. In that case, the laser induced fusion of the gold nanoparticles led to irreversible color changes from red to blue, providing interesting photochromatic pigments which can be used in paints or for memory storage using visible light.

\section{Conclusion and Perspectives}

Nowadays, as Eustis and El-Sayed have pointed out, ${ }^{2}$ gold nanoparticles seem indeed to be more precious than pretty gold. Although gold nanoparticles have been employed in alchemy and arts for more than twenty centuries, the advent of nanotechnology led to an explosion of interest in the field, as reflected by the exponential growth in the number of published articles in practically all areas of knowledge. Gold nanoparticles exhibit remarkable stability and can be prepared in many different ways for the exploitation of their size and shape-dependent properties. In addition, they can be chemically modified by interaction of the surface atoms with external agents or ligands, in a similar way as their corresponding metal complexes. This close parallelism allows the design of metal nanoparticles linked to metal complexes, according to a supramolecular approach, for specific applications as sensors, medical imaging and diagnostics, catalysis, and as building blocks for hybrid inorganic-organic-biological advanced materials.

In special, gold nanoparticles belong to the class of plasmon accessible nanoparticles where the electrons 
can oscillate in resonance with the exciting visible light frequency, generating enhanced electric fields and anomalous scattering and absorption phenomena. The sensibility of the plasmon resonance to the adsorbed species is a key point for developing applications of gold nanoparticles in chemical and biological sensors. However, the optical and dynamic properties of gold nanoparticles are not yet completely understood. Although the characteristics of individual nanoparticles have been extensively studied experimentally and theoretically, the aggregates exhibit new, different properties. In most practical situations, such particle-particle interactions are very important, and sometimes they are dominant. This is the case of the surface enhanced Raman scattering, which depends on the existence of "hot spots" located in the interfacial separation of the agglomerated nanoparticles. Finally, from the many interesting examples reported in this paper, a new exciting coordination chemistry can be envisaged, combining metal nanoparticles and complexes in the light of supramolecular and surface plasmon resonance effects. Additionally, new exciting heterohybrid systems encompassing associated metal (Au, $\mathrm{Ag}$ ) nanoparticles, magnetic nanoparticles, quantum dots $(\mathrm{CdS}, \mathrm{CdTe})$ and semiconducting nanoparticles $\left(\mathrm{TiO}_{2}\right)$ can be developed based on the coordination chemistry strategy.

\section{Acknowledgments}

The financial support from FAPESP, CNPq and PETROBRAS is gratefully acknowledged.

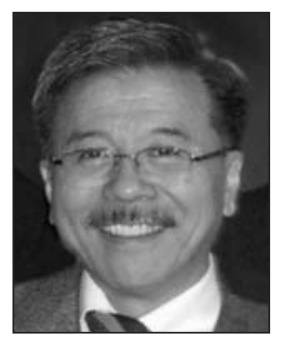

Henrique E. Toma is Professor of Chemistry at the Institute of Chemistry, University of São Paulo. He obtained his PhD in 1974 by working on inorganic chemistry, kinetics and catalysis. After 1980 he incorporated bioinorganic chemistry and supramolecular chemistry in his research interests, focusing mainly on macrocyclic compounds, porphyrins and biomimetic models involved in electron transfer and energy conversion. He is now working on molecular and supramolecular materials, aiming at the development of processes and nanotechnological devices.

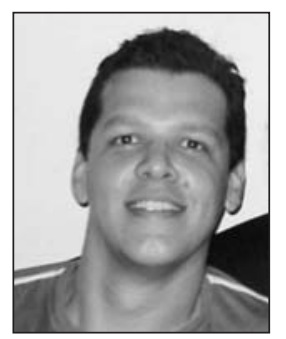

Vitor M. Zamarion obtained his MSc degree in 2008, and is currently working in the development of plasmon nanoparticles and SERS sensors.

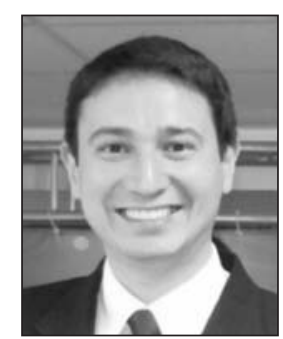

Sergio H. Toma obtained his PhD in 2007, and received the Best National Dissertation Thesis Prize from the Brazilian agency CAPES. He is currently working on heterohybrid supramolecular chemistry encompassing plasmon resonance effects.

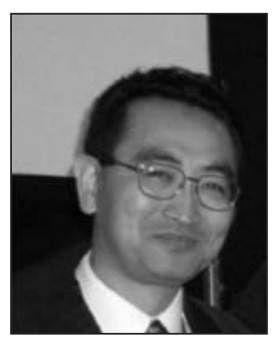

Koiti Araki is Professor of Chemistry at the Institute of Chemistry, University of São Paulo. He obtained his PhD in 1994, and his current interests are concentrated on molecular nanotechnology, particularly the design of supramolecular materials and interfaces for the development of chemical sensors and biomedical applications.

\section{References}

1. Faraday, M.; Philos. Trans. R. Soc. 1857, 147, 145.

2. Eustis, S.; El-Sayed, M. A.; Chem. Soc. Rev. 2006, 35, 209.

3. Stewart, M. E.; Anderton, C. R.; Thompson, L. B.; Maria, J.; Gray, S. K.; Rogers, J. A.; Nuzzo, R. G.; Chem. Rev. 2008, 108, 494; Zhao, J.; Pinchuk, A. O.; McMahon, J. M.; Li, S. Z.; Ausman, L. K.; Atkinson, A. L.; Schatz, G. C.; Acc. Chem. Res. 2008, 41, 1710; Zhang, J. Z.; Noguez, C.; Plasmonics 2008, 3, 127; Camden, J. P.; Dieringer, J. A.; Zhao, J.; Van Duyne, R. P.; Acc. Chem. Res. 2008, 41, 1653; Lin, X. M.; Cui, Y.; Xu, Y. H.; Ren, B.; Tian, Z. Q.; Anal. Bioanal. Chem. 2009, 394, 1729; Noguez, C.; Garzon, I. L.; Chem. Soc. Rev. 2009, 38, 757.

4. Daniel, M. C.; Astruc, D.; Chem. Rev. 2004, 104, 293.

5. Murphy, C. J.; San, T. K.; Gole, A. M.; Orendorff, C. J.; Gao, J. X.; Gou, L.; Hunyadi, S. E.; Li, T.; J. Phys. Chem. B 2005, 109, 13857.

6. Chon, J. W. M.; Bullen, C.; Zijlstra, P.; Gu, M.; Adv. Funct. Mater. 2007, 17, 875; Chen, M. S.; Goodman, D. W.; Acc. Chem. Res. 2006, 39, 739.

7. Wanunu, M.; Popovitz-Biro, R.; Cohen, H.; Vaskevich, A.; Rubinstein, I.; J. Am. Chem. Soc. 2005, 127, 9207.

8. Cao, R.; Diaz-Garcia, A. M.; Coord. Chem. Rev. 2009, 253, 1262.

9. Brus, L.; Acc. Chem. Res. 2008, 41, 1742.

10. Aroca, R., Surface-Enhanced Vibrational Spectroscopy, John Wiley \& Sons: Chichester, 2006, p. 233.

11. Ghosh, S. K.; Pal, T.; Chem. Rev. 2007, 107, 4797.

12. Turkevich, J.; Stevenson, P. C.; Hillier, J.; Disc. Faraday Soc. 1951, 55 . 
13. Frens, G.; Nature, Phys. Sci. 1973, 241, 20.

14. Brust, M.; Fink, J.; Bethell, D.; Schiffrin, D. J.; Kiely, C.; J. Chem. Soc., Chem. Commun. 1995, 1655.

15. Araki, K.; Mizuguchi, E.; Tanaka, H.; Ogawa, T.; J. Nanosci. Nanotech. 2006, 6, 708.

16. Jin, R. C.; Cao, Y. W.; Mirkin, C. A.; Kelly, K. L.; Schatz, G. C.; Zheng, J. G.; Science 2001, 294, 1901.

17. Pileni, M. P.; Langmuir 1997, 13, 3266.

18. Bhatt, A. I.; Mechler, A.; Martin, L. L.; Bond, A. M.; J. Mater. Chem. 2007, 17, 2241.

19. Schrekker, H. S.; Gelesky, M. A.; Stracke, M. P.; Schrekker, C. M. L.; Machado, G.; Teixeira, S. R.; Rubim, J. C.; Dupont, J.; J. Colloid Interface Sci. 2007, 316, 189.

20. Pileni, M. P.; Nature Materials 2003, 2, 145.

21. Toma, H. E.; Bonifacio, L. D.; Anaissi, F. J.; Quim. Nova 2005, 28, 897; Duffy, J. A., Bonding, Energy Levels and Bands in Inorganic Solids, Longman: Essex, 1990.

22. Mie, G.; Annalen Der Physik 1908, 25, 377.

23. Huo, F. W.; Lytton-Jean, A. K. R.; Mirkin, C. A.; Adv. Mater. 2006, 18, 2304; Xu, X. Y.; Rosi, N. L.; Wang, Y. H.; Huo, F. W.; Mirkin, C. A.; J. Am. Chem. Soc. 2006, 128, 9286.

24. Lal, S.; Clare, S. E.; Halas, N. J.; Acc. Chem. Res. 2008, 41, 1842; Jain, P. K.; El-Sayed, M. A.; Nano Lett. 2008, 8, 4347; Cheon, J.; Lee, J. H.; Acc. Chem. Res. 2008, 41, 1630; ElSayed, I. H.; Huang, X. H.; El-Sayed, M. A.; Nano Lett. 2005, 5,829 .

25. Garnett, J. C. M.; Proc. R. Soc. London 1904, 73, 443; Garnett, J. C. M.; Proc. R. Soc. London, Ser. A 1905, 76, 370; Garnett, J. C. M.; Phil. Trans. R. Soc. London, Ser. A 1906, 205, 237.

26. Purcell, E. M.; Pennypacker, C. R.; Astrophys. J. 1973, 186, 705.

27. Kerker, M.; Appl. Opt. 1980, 19, 4137; Kerker, M.; Wang, D. S.; Chew, H.; Appl. Opt. 1980, 19, 4159.

28. Moskovits, M.; J. Chem. Phys. 1982, 77, 4408; Moskovits, M.; J. Chem. Phys. 1983, 79, 1558; Moskovits, M.; Rev. Modern Phys. 1985, 57, 783.

29. Corio, P.; Andrade, G. F. S.; Diogenes, I. C. N.; Moreira, I. S.; Nart, F. C.; Temperini, M. L. A.; J. Electroanal. Chem. 2002, 520, 40; Diogenes, I. C. N.; de Carvalho, I. M. M.; Longhnotti, E.; Lopes, L. G. F.; Temperini, M. L. A.; Andrade, G. F. S.; Moreira, I. S.; J. Electroanal. Chem. 2007, 605, 1.

30. Diogenes, I. C. N.; de Sousa, J. R.; de Carvalho, I. M. M.; Temperini, M. L. A.; Tanaka, A. A.; Moreira, I. D. S.; J. Chem. Soc., Dalton Trans. 2003, 2231.

31. Aravind, P. K.; Metiu, H.; J. Phys. Chem. 1982, 86, 5076; Aravind, P. K.; Metiu, H.; Surf. Sci. 1983, 124, 506; Aravind, P. K.; Nitzan, A.; Metiu, H.; Surf. Sci. 1981, 110, 189.

32. Otto, A.; Mrozek, I.; Grabhorn, H.; Akemann, W.; J. Phys., Cond. Matter 1992, 4, 1143.

33. Creutz, C.; Brunschwig, B. S.; Sutin, N.; J. Phys. Chem. B 2005, 109, 10251.
34. Lombardi, J. R.; Birke, R. L.; Acc. Chem. Res. 2009, 42, 734.

35. Albrecht, A. C.; J. Chem. Phys. 1961, 34, 1476.

36. Xu, H. X.; Aizpurua, J.; Kall, M.; Apell, P.; Phys. Rev. E 2000, 62, 4318; Xu, H. X.; Bjerneld, E. J.; Kall, M.; Borjesson, L.; Phys. Rev. Lett. 1999, 83, 4357.

37. Michaels, A. M.; Nirmal, M.; Brus, L. E.; J. Am. Chem. Soc. 1999, 121, 9932.

38. Verwey, E. J. W.; Overbeek, J. T. G., Theory of the Stability of Lyophobic Colloids, Dover: New York, 2000.

39. Templeton, A. C.; Hostetler, M. J.; Warmoth, E. K.; Chen, S. W.; Hartshorn, C. M.; Krishnamurthy, V. M.; Forbes, M. D. E.; Murray, R. W.; J. Am. Chem. Soc. 1998, 120, 4845; Otsuka, H.; Akiyama, Y.; Nagasaki, Y.; Kataoka, K.; J. Am. Chem. Soc. 2001, 123, 8226; Johnson, S. R.; Evans, S. D.; Mahon, S. W.; Ulman, A.; Langmuir 1997, 13, 51; Chen, S. H.; Kimura, K.; Langmuir 1999, 15, 1075.

40. Descalzo, A. B.; Martinez-Manez, R.; Sancenon, R.; Hoffmann, K.; Rurack, K.; Angew. Chem. Int. Ed. 2006, 45, 5924.

41. Meyer, M.; Le Ru, E. C.; Etchegoin, P. G.; J. Phys. Chem. B 2006, 110, 6040.

42. Weisbecker, C. S.; Merritt, M. V.; Whitesides, G. M.; Langmuir 1996, 12, 3763.

43. Viudez, A. J.; Madueno, R.; Blazquez, M.; Pineda, T.; J. Phys. Chem. C 2009, 113, 5186; Viudez, A. J.; Madueno, R.; Pineda, T.; Blazquez, M.; J. Phys. Chem. B 2006, 110, 17840.

44. Bellino, M. G.; Calvo, E. J.; Gordillo, G.; Phys. Chem. Chem. Phys. 2004, 6, 424.

45. Nunes, F. S.; Bonifacio, L. D.; Araki, K.; Toma, H. E.; Inorg. Chem. 2006, 45, 94.

46. Kim, Y. J.; Johnson, R. C.; Hupp, J. T.; Nano Lett. 2001, 1, 165.

47. Lin, S. Y.; Liu, S. W.; Lin, C. M.; Chen, C. H.; Anal. Chem. 2002, 74, 330 .

48. Toma, H. E.; Batista, A. A.; Gray, H. B.; J. Am. Chem. Soc. 1982, 104, 7509.

49. Toma, H. E.; Creutz, C.; Inorg. Chem. 1977, 16, 545.

50. Toma, H. E.; Malin, J. M.; Inorg. Chem. 1973, 12, 1039.

51. Toma, H. E.; Malin, J. M.; J. Am. Chem. Soc. 1975, 97, 288.

52. Toma, H. E.; Malin, J. M.; Giesbrecht, E.; Inorg. Chem. 1973, 12, 2084.

53. Toma, H. E.; Takasugi, M. S.; Polyhedron 1982, 1, 429.

54. Toma, S. H.; Bonacin, J. A.; Araki, K.; Toma, H. E.; Eur. J. Inorg. Chem. 2007, 3356.

55. Rubim, J. C.; Corio, P.; Ribeiro, M. C. C.; Matz, M.; J. Phys. Chem. 1995, 99, 15765.

56. Toma, H. E.; J. Chem. Soc., Dalton Trans. 1980, 471; Toma, H. E.; Can. J. Chem., Rev. Can. Chimie 1979, 57, 2079.

57. Szacilowski, K.; Macyk, W.; Hebda, M.; Stochel, G.; Chemphyschem 2006, 7, 2384.

58. Henke, K. R.; Hutchison, A. R.; Krepps, M. K.; Parkin, S.; Atwood, D. A.; Inorg. Chem. 2001, 40, 4443. 
59. Matlock, M. M.; Henke, K. R.; Atwood, D. A.; Robertson, D.; Water Res. 2001, 35, 3649; Bailey, J. R.; Hatfield, M. J.; Henke, K. R.; Krepps, M. K.; Morris, J. L.; Otieno, T.; Simonetti, K. D.; Wall, E. A.; Atwood, D. A.; J. Organomet. Chem. 2001, $623,185$.

60. Zamarion, V. M.; Timm, R. A.; Araki, K.; Toma, H. E.; Inorg. Chem. 2008, 47, 2934.

61. Lehn, J.-M., Supramolecular Chemistry, VCH: Weinheim, 1995; Toma, H. E.; Araki, K.; Prog. Inorg. Chem. 2009, 56, 379.

62. Forster, R. J.; Keyes, T. E.; Coord. Chem. Rev. 2009, 253, 1833.

63. Diogenes, I. C. N.; Nart, F. C.; Barreto, M.; Temperini, M. L. A.; Moreira, I. D.; J. Solid State Electrochem. 2007, 11, 1585; Diogenes, I. C.; Nart, F. C.; Temperini, M. L. A.; Moreira, I. D.; Electroanalysis 2002, 14, 153.

64. Wang, S.; Sim, W. S.; Langmuir 2006, 22, 7861.

65. Knight, E. R.; Leung, N. H.; Thompson, A. L.; Hogarth, G.; Wilton-Ely, J.; Inorg. Chem. 2009, 48, 3866.

66. Ingram, R. S.; Hostetler, M. J.; Murray, R. W.; J. Am. Chem. Soc. 1997, 119, 9175.

67. Labande, A.; Astruc, D.; Chem. Commun. 2000, 1007.

68. Daniel, M. C.; Ruiz, J.; Nlate, S.; Blais, J. C.; Astruc, D.; J. Am. Chem. Soc. 2003, 125, 2617.

69. Angelici, R. J.; Lazar, M.; Inorg. Chem. 2008, 47, 9155.

70. Costa, J. C. S.; Ando, R. A.; Sant'Ana, A. C.; Rossi, L. M.; Santos, P. S.; Temperini, M. L. A.; Corio, P.; Phys. Chem. Chem. Phys. 2009, 11, 7491.

71. Mayer, C. R.; Cucchiaro, G.; Jullien, J.; Dumur, F.; Marrot, J.; Dumas, E.; Secheresse, F.; Eur. J. Inorg. Chem. 2008, 3614; Mayer, C. R.; Dumas, E.; Michel, A.; Secheresse, F.; Chem. Commun. 2006, 4183; Mayer, C. R.; Dumas, E.; Miomandre, F.; Meallet-Renault, R.; Warmont, F.; Vigneron, J.; Pansu, R.; Etcheberry, A.; Secheresse, F.; New J. Chem. 2006, 30, 1628; Mayer, C. R.; Dumas, E.; Secheresse, F.; J. Colloid Interface Sci. 2008, 328, 452.

72. Dong, T. Y.; Huang, C. L.; Chen, C. P.; Lin, M. C.; J. Organomet. Chem. 2007, 692, 5147.
73. Lewis, D. J.; Day, T. M.; MacPherson, J. V.; Pikramenou, Z.; Chem. Commun. 2006, 1433.

74. Marubayashi, K.; Takizawa, S.; Kawakusu, T.; Arai, T.; Sasai, H.; Org. Lett. 2003, 5, 4409.

75. Debouttiere, P. J.; Roux, S.; Vocanson, F.; Billotey, C.; Beuf, O.; Favre-Reguillon, A.; Lin, Y.; Pellet-Rostaing, S.; Lamartine, R.; Perriat, P.; Tillement, O.; Adv. Funct. Mater. 2006, 16, 2330.

76. Thomas, K. G.; Kamat, P. V.; Acc. Chem. Res. 2003, 36, 888.

77. Pramod, P.; Sudeep, P. K.; Thomas, K. G.; Kamat, P. V.; J. Phys. Chem. B 2006, 110, 20737.

78. Krausz, E.; Ferguson, J.; Prog. Inorg. Chem. 1989, 37, 293.

79. Huang, T.; Murray, R. W.; Langmuir 2002, 18, 7077.

80. Hallett, A. J.; Christian, P.; Jones, J. E.; Pope, S. J. A.; Chem. Commun. 2009, 4278.

81. Watanabe, K.; Menzel, D.; Nilius, N.; Freund, H. J.; Chem. Rev. 2006, 106, 4301; Sibbald, M. S.; Chumanov, G.; Cotton, T. M.; J. Phys. Chem. 1996, 100, 4672; Kurita, H.; Takami, A.; Koda, S.; Appl. Phys. Lett. 1998, 72, 789; Takami, A.; Kurita, H.; Koda, S.; J. Phys. Chem. B 1999, 103, 1226; Mafune, F.; Kohno, J.; Takeda, Y.; Kondow, T.; J. Phys. Chem. B 2001, 105, 9050; Mafune, F.; Kohno, J.; Takeda, Y.; Kondow, T.; J. Phys. Chem. B 2003, 107, 12589; Mafune, F.; Kohno, J. Y.; Takeda, Y.; Kondow, T.; J. Phys. Chem. B 2002, 106, 7575; Mafune, F.; Kohno, J. Y.; Takeda, Y.; Kondow, T.; J. Phys. Chem. B 2002, 106, 8555; El-Sayed, M. A.; Acc. Chem. Res. 2001, 34, 257; Link, S.; Hathcock, D. J.; Nikoobakht, B.; El-Sayed, M. A.; Adv. Mater. 2003, 15, 393.

82. Bonifacio, L. S.; Gordijo, C. R.; Constantino, V. R. L.; Silva, D. O.; Kiyohara, P. K.; Araki, K.; Toma, H. E.; J. Nanosci. Nanotech. 2008, 8, 274.

Received: November 5, 2009 Web Release Date: April 22, 2010

FAPESP helped in meeting the publication costs of this article. 